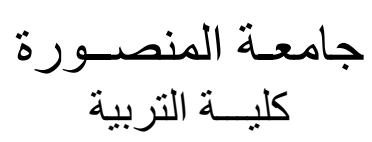

\title{
واقع استخدام التكنولوجيا الحديثة في ميدان التربية الخاصة في ظل جائحة كورونا بمدينة جدة السعودية.
}

\author{
إعداد \\ خالا حبني ياسين الثهري \\ عبد العزيز محمد سعيد الغامدي \\ معلم تربية خاصة (صعوبات تعلم) \\ معلم تربية خاصة (صعوبات التعلم)

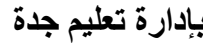 \\ بمكة المكرمة بلمبات
}

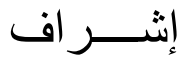

$$
\begin{aligned}
& \text { د/يوسف بن هذال الذيابي }
\end{aligned}
$$

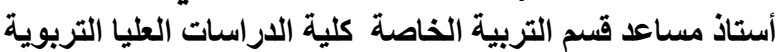

$$
\begin{aligned}
& \text { جامعة الملك عبد العزيز- المملكة العربية السعودية الثرات العية }
\end{aligned}
$$

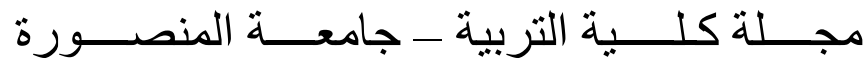

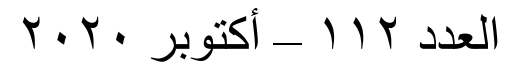


و اقع استخدام التكنولوجيا الحديثة في ميدان التربية الخاصة في ظل جائحة

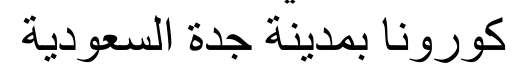

خالا حبني ياسين الثهري

عبد العزيز محمد سعيد الغامدي

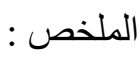

استهاف البحث إلسى التعرف إلسى مدى فعالية التكنولوجيا في تعليم ذوي الاحتياجات. وتصنيف

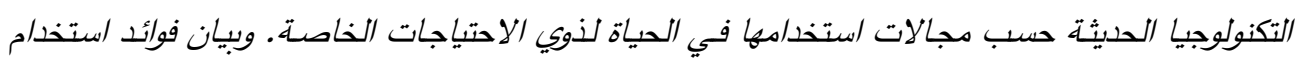

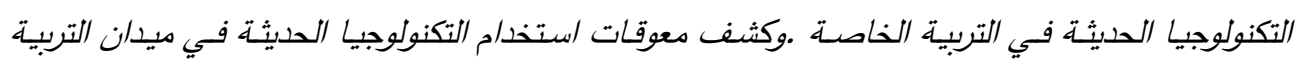
الخاصة. والتعرف إلى دور التكنولوجيا في ظل جائحة كورونا في التعليم ذوي الاحتياجات الخاصة لـ ـ يتمثل

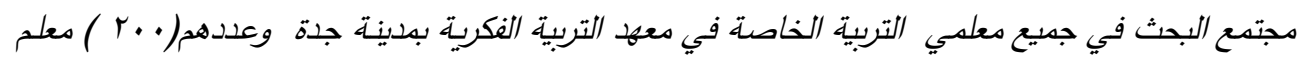

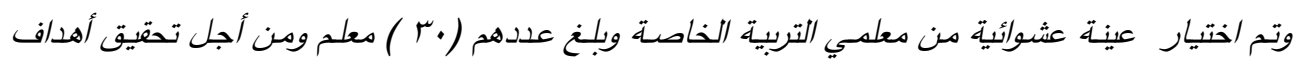

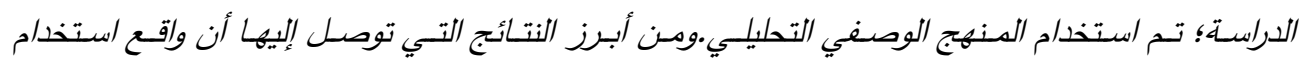

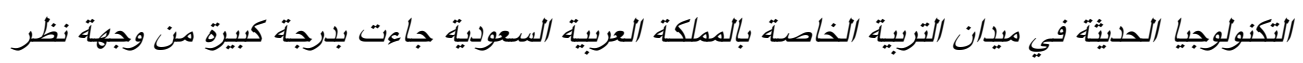

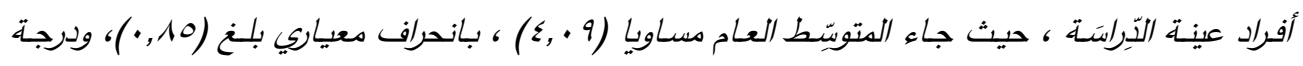

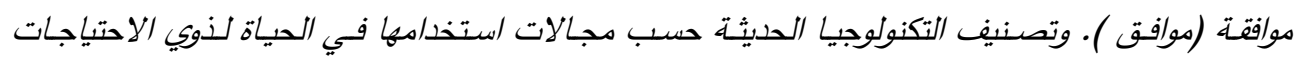

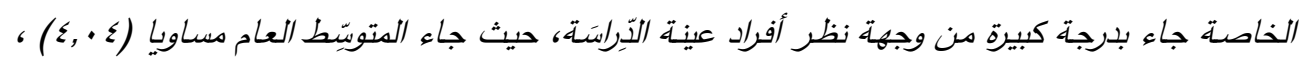
بانحراف معياري بلغ (19, •)، ودرجة موافقة (موافق ) .

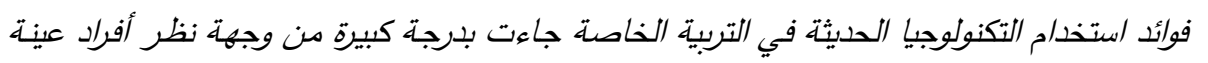

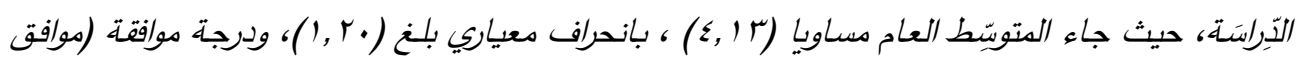

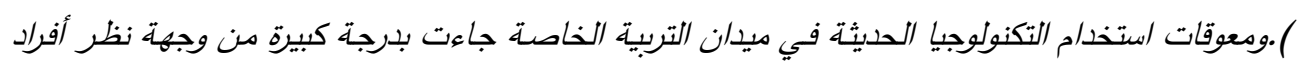

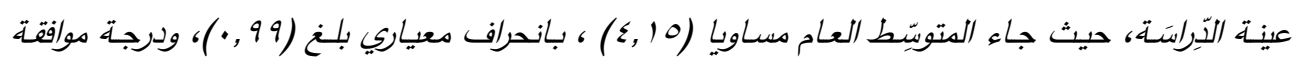

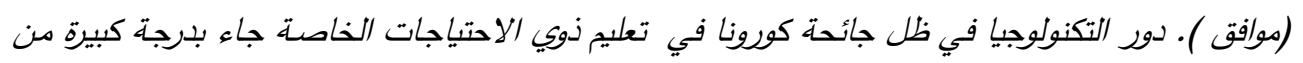

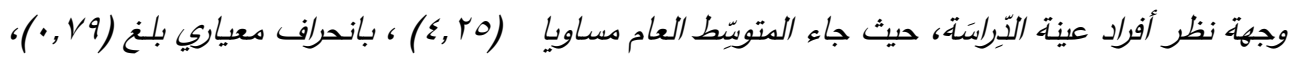

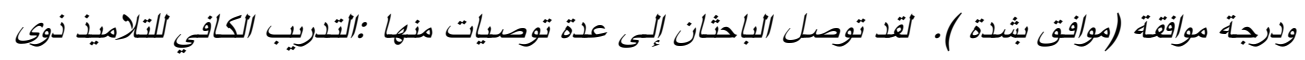

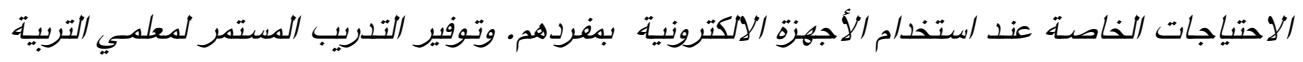
الخاصة على استخدام الوسائل التعليية التكنولوجية. الكلمات الفتتاحية: التكنولوجيا الحديثة، التربية الخاصة، جائحة كورونا، الدملكة العربية السعودية. 
يتّّم العصر الحالي بالتغير السريع في كافة مجالات الحياة لاسيما مجال التعليم، الأمر الأي فرض على المؤسسات التربوية مواكبة هذه التغيرات والاستفادة منها قدر الإمكان؛ لمساعدة

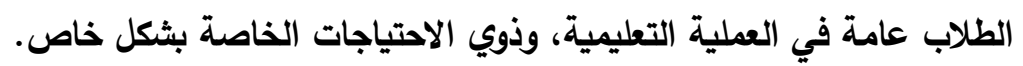

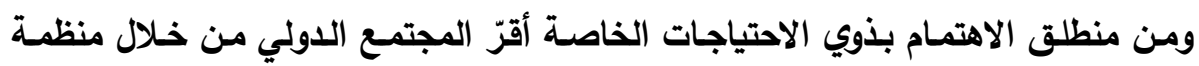

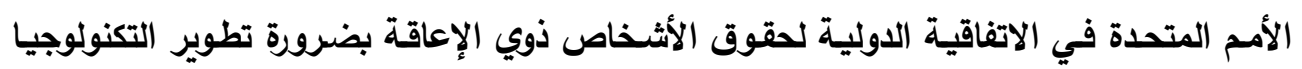

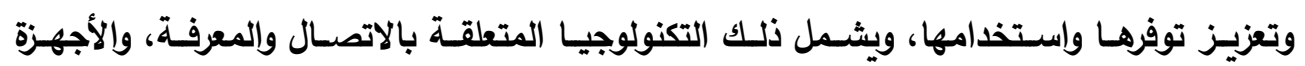

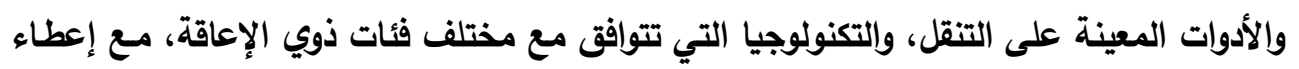

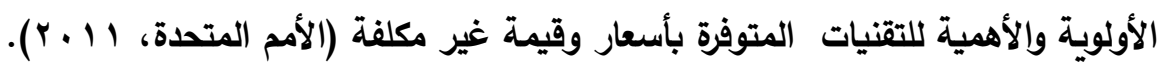
أمـا في المملكة العربية السعودية فقد حرصت على توفير التكنولوجيا المسـاعدة وتقديم

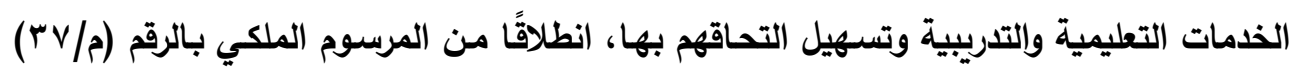

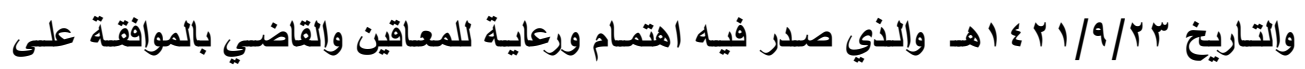

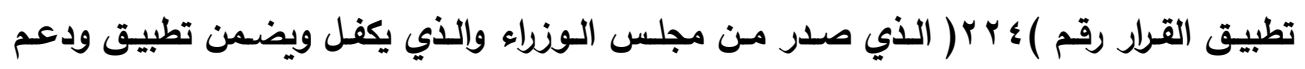
الجهود والأعمال المميزة في مجال تعليم المعاقين ورعايتهح وتأهيلهم (مركز الملك سلمان لألأبحاث

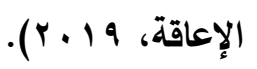

ولا يقتصر مفهوم التكنولوجيا على الإكترونيات المعقدة، وإنمـا كافـة الأجهزة والوسـائل

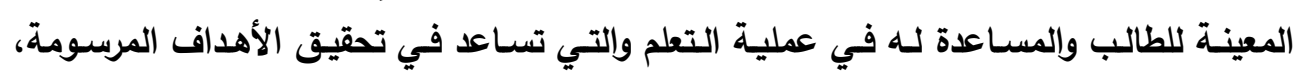

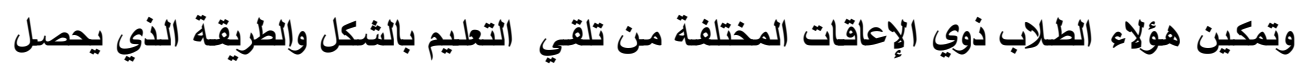

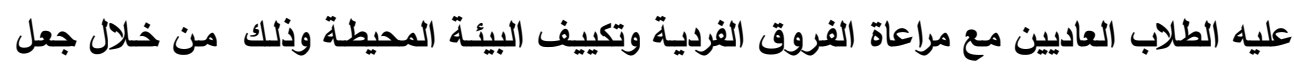

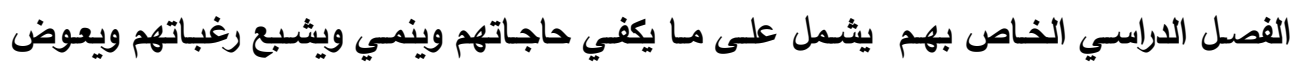

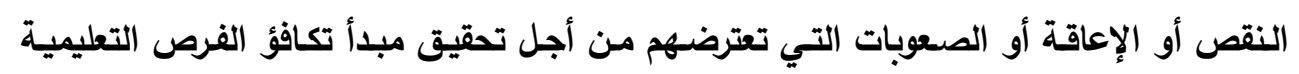

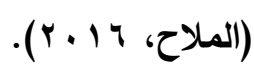

وعلى الرغم من أهمية التكنولوجيا الحديثة في العملية التعليمية لذوي الاحتياجات الخاصـة

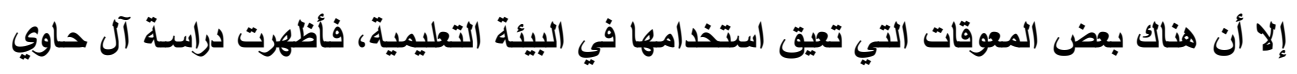

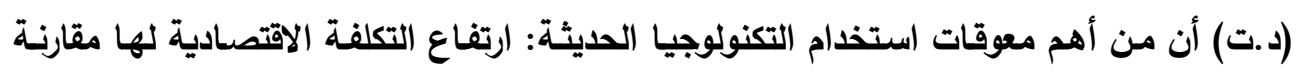

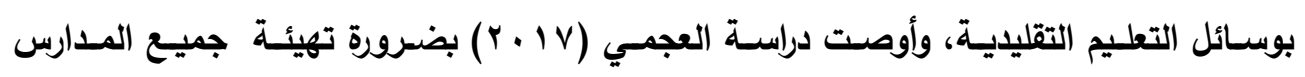

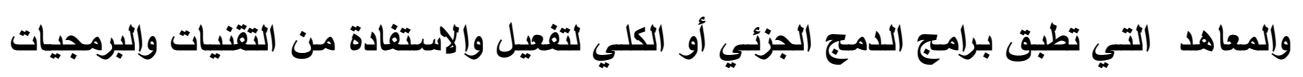
الحديثة في مجال ذوي الإعاقة . 
قد أثر انتشار جائحة كورونا تأثيرا سريعا على الحياة اليومية بكل نشاطاتها، فقد أثر على

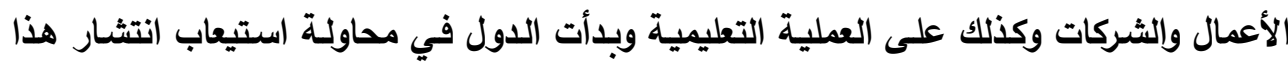

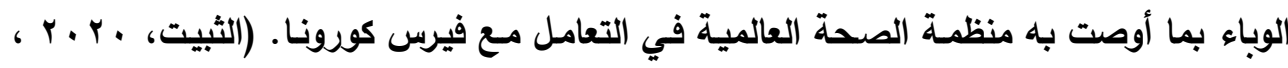

في ظل الظروف الطارئـة التي يمر بها العالم بسبب انتثـار جائحسة كورونـا (كوفيد-9 (1) ) والذي أدى إلى إغلاق المدراس في كافة أرجاء العالم، تعطلت الدروس بصفة جزئية لمدة من

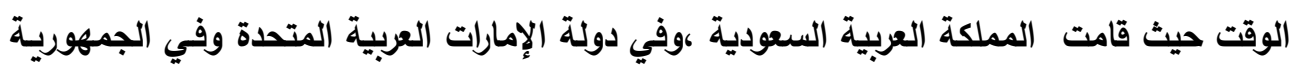

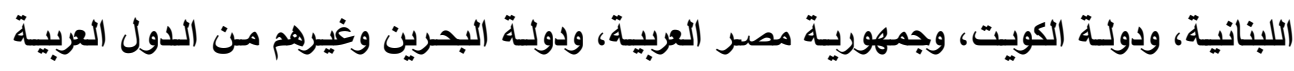

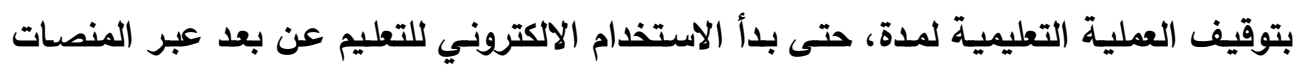

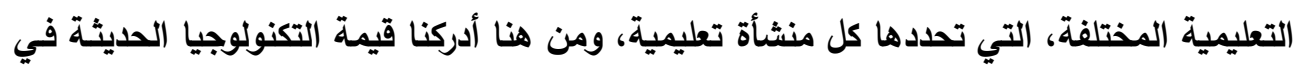

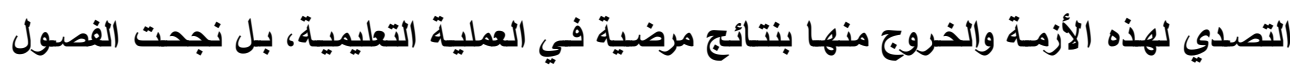

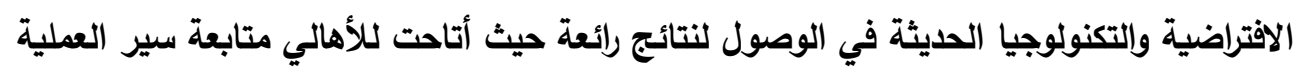
التعليمية لأبنائهم، ومعرفة أوجه القصور والقوة عندهم.

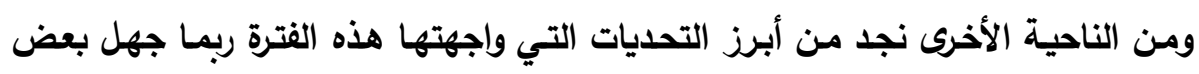

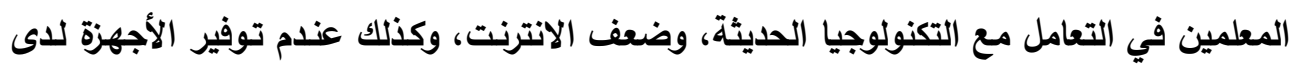

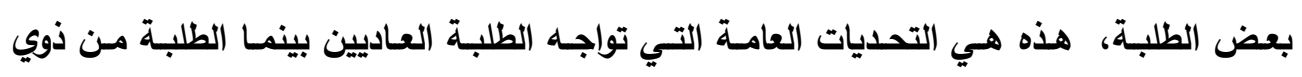
الاحتياجات الخاصة لايهم تحديات ومعوقات بثكل أكبر من ذلك ومنها بعض المكفوفين يحتاج

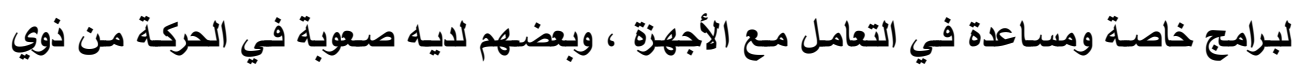

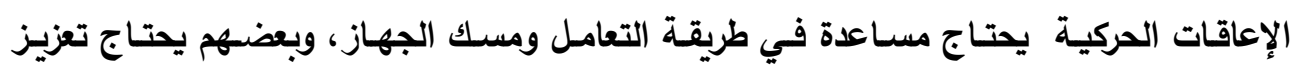
ورعاية للمتابعة.

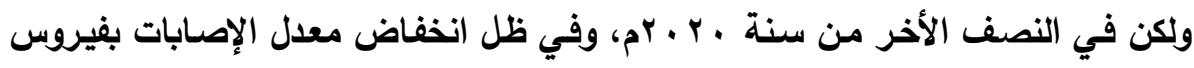

كورونا المستجد يأخذوا بعض العصص في المعهد وبعضها عبر المنصات الاجتماعية.

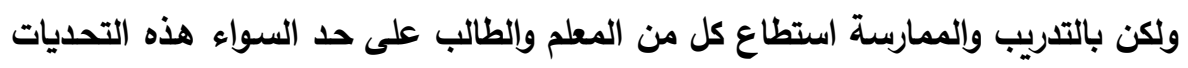

أو بعضها.

ومن هنا يسعى الباحثان في هذا البحث إلى الكثف عن واقع استخدام التكنولوجيا الحديثة

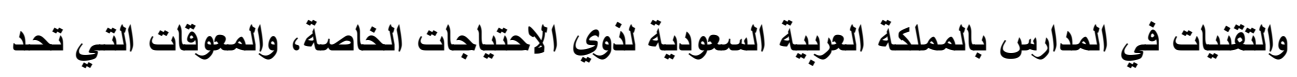

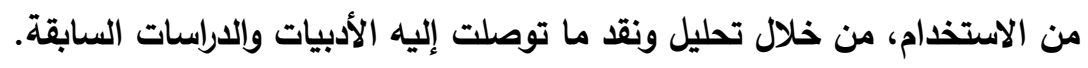


ارتبطت أزمــة جائحسة كورونـا بتعطيل المـدراس والكثير مـن الأنثطة الاقتصـادية، وبـز

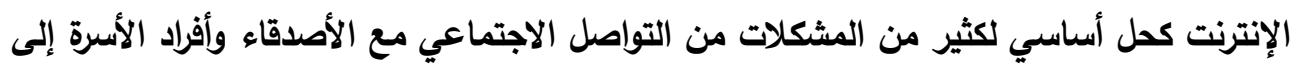

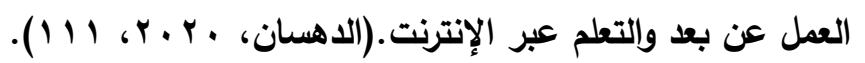

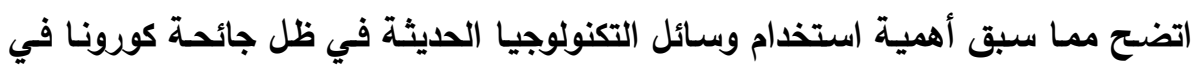

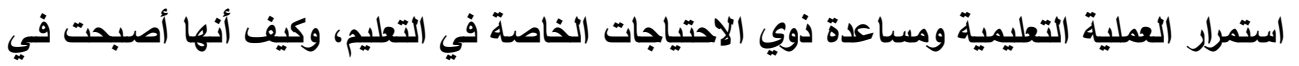
وقت قياسي أهم مداخل تطور واستمرار التعليم بالعالم كله وتبين لنا نجاح استخدامها في في المملكة العربية السعودية، لذا قرر الباحثان إجراء دراسـة للتعرف على واقع استخدام التكنولوجيا العديثة في ميدان التربية الخاصة في ظل جائحة كورونا بالمملكة العربية السعودية. أسئلة البحث:

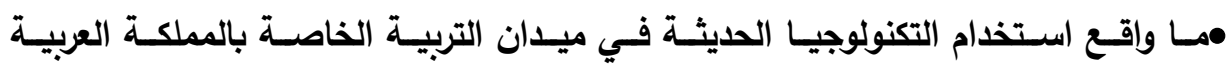

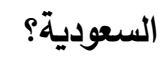

•مـا تصنيف التكنولوجيا الحديثة حسب مجـالات استخدامها في الحياة لذوي الاحتياجـات

$$
\text { الخاصة ؟ }
$$

مما فوائد استخدام التكنولوجيا العديثة في التربية الخاصة ؟ •ما معوقات استخدام التكنولوجيا الحديثة في ميدان التربية الخاصة؟

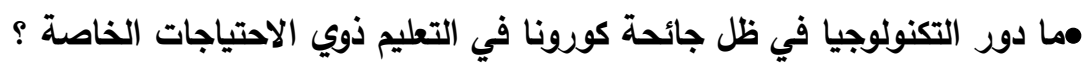
أهداف البحث : 1. التعرف إلى مدى فعالية التكنولوجيا في تعليم ذوي الاحتياجات.

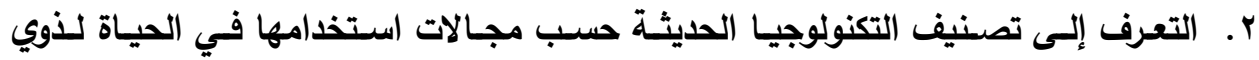
الاحتياجات الخاصة. r. بيان فوائد استخدام التكنولوجيا الحديثة في التربية الخاصة . ع ـ كشف معوقات استخدام التكنولوجيا الحديثة في ميدان التربية الخاصة. هـ التعرف إلى دور التكنولوجيا في ظل جائحة كورونا في التعليم ذوي الاحتياجات الخاصة فئه

من أجل تحقيق أهداف الدراسـة؛ تم استخدام المنهج الوصفي التحليلي ويعرف المنهج

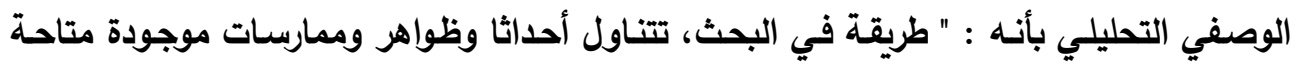
للدراسة والقياس، كما هي، دون تدخل الباحث في مجرياتها، إذ يستطيع الباحث أن يتفاعل معها 
فيصفها" (زيدان، سلمان، تطوير التعليم الجامعي لتنمية المجتمعات في ضوء إدارة الجودة، مركز

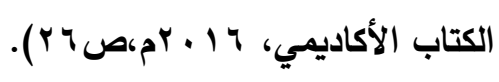

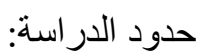

الدد الموضوعي: اقتصر الموضوع على التعرف إلى واقع استخدام التكنولوجيا الحديثة

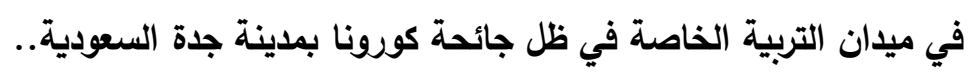

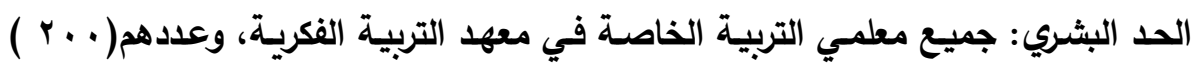

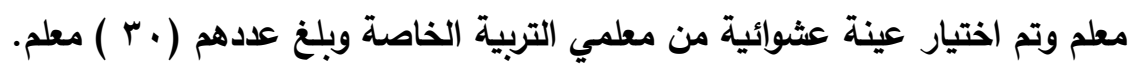

الحد المكاني: بمدينة جدة بالمملكة العربية السعودية.

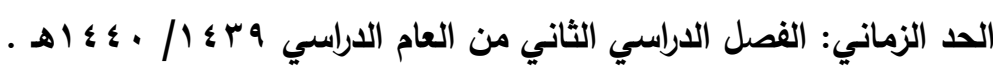

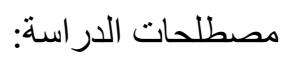

جائحة: التعريف الاصطلاحي : أصابته جائحة أي بلية، تهلكة، داهية. (معجم المغني، ال

.99

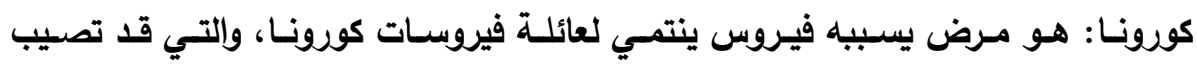

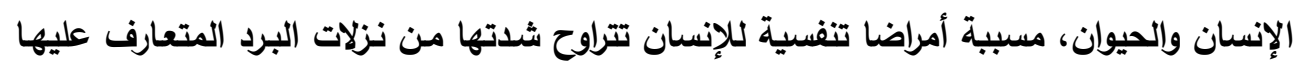

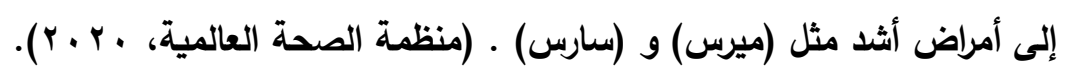

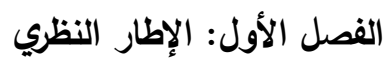

مفهوم التقنيات التعليمية والتكنولوجية الحديثة لذوي الاعاقات المختلفة:

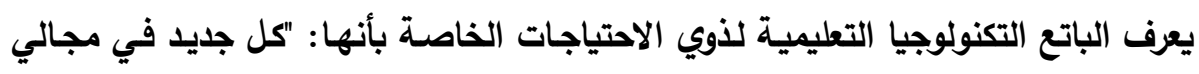

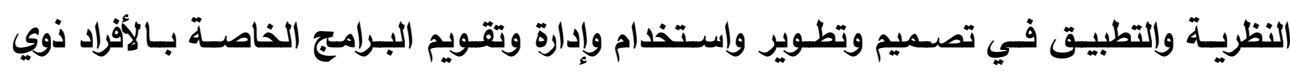

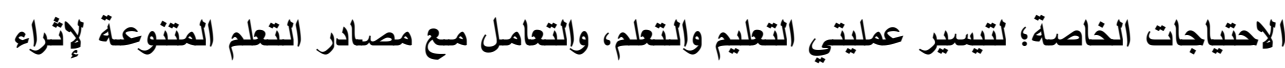

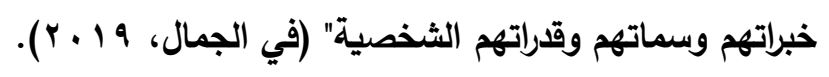

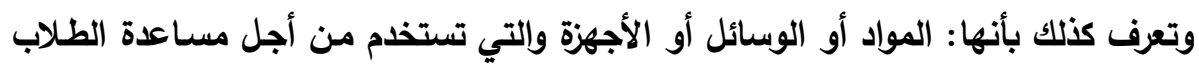

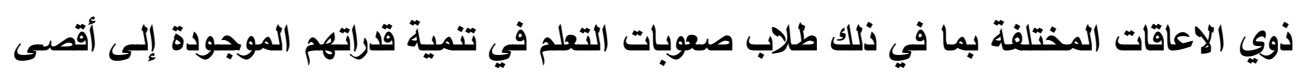

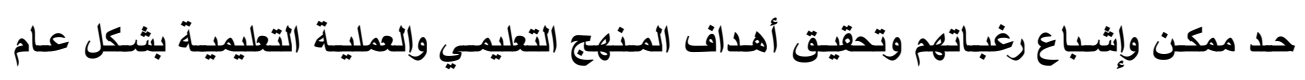

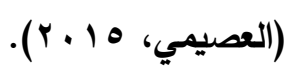

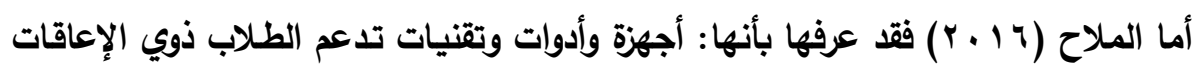

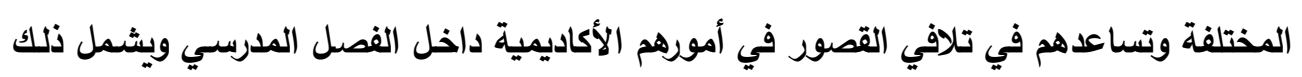


مهارات القراءة والكتابة والتهجئة مما ييسر لهم ويسهل سير العملية التعليمية بالثكل المطلوب والإيجابي.

ويعرف الباحثان في هذه الورقة النقدية التقنيات التعليمية بأنها: أدوات ووسائل يستخدمها

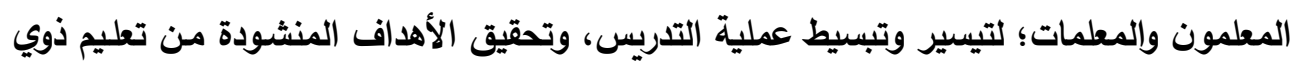
الاحتياجات الخاصة.

وتصنف التقنيات الحديثة والتكنولوجيا حسب المهارات الحياتية لذوي الاحتياجات الخاصـة وطريقة استخدامهم في أمورهم اليومية إلى :

يصنف الثراري ( د.ت) التكنولوجيا الحديثة حسب مجئ إلماتلات استخدامها في الحياة لذوي الاحتياجات الخاصة كالتالي: التئن

1- التكنولوجيا المتعلقة بالاتصـال: ويكون هذا إذا أراد ذوي الإعاقة السمعية انتقال البيانات

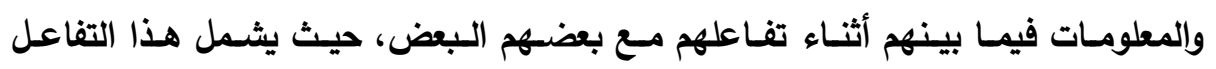

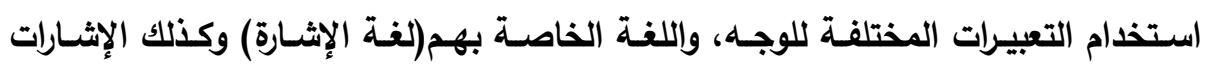

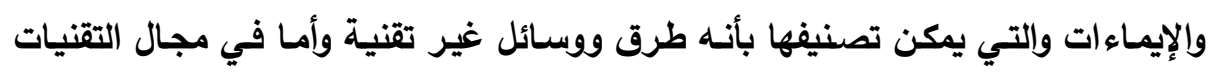

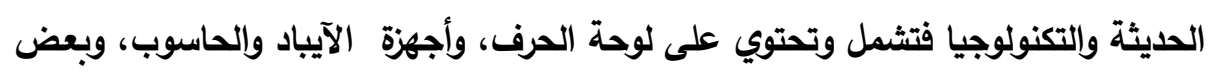
البرامج التقنية.

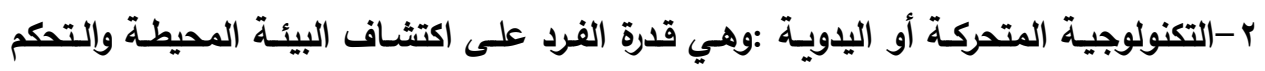

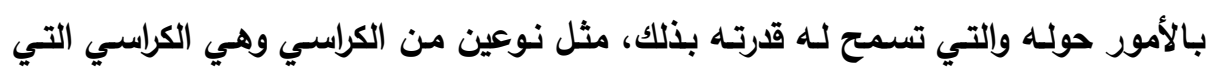

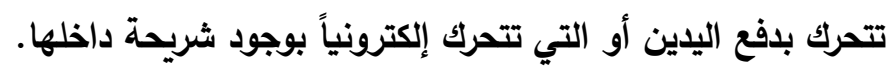

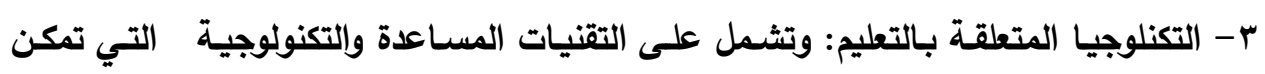

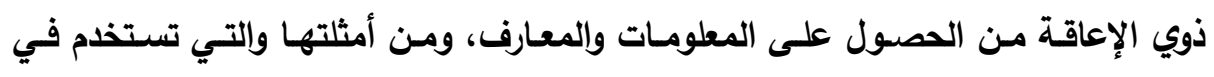
المعاهد والمدارس: جهاز مشر يتم استخدامه بثكل يدوي، والألعاب والبرامج الإكترونية الإنية

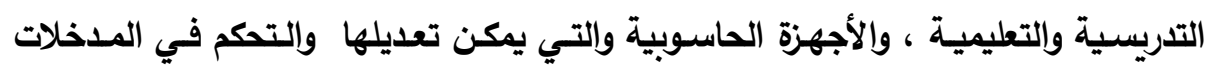

$$
\text { والمخرجات فيها. }
$$

؛ -التكنلوجيا المتعلقة بالمهن المختلفة: وتحوي على الأجهزة الميسرة والمساعدة والتي يمكن

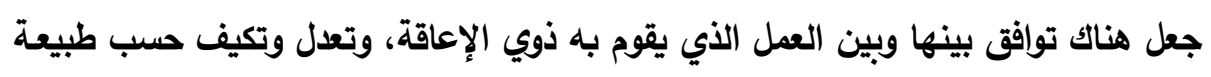

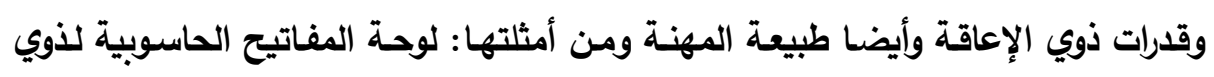
الإعاقة السمعية. 
ه-تكنولوجية استقلالية الفرد ذوي الإعاقة: وهي التي تمكن مستخدمها من ذوي الإعاقة من

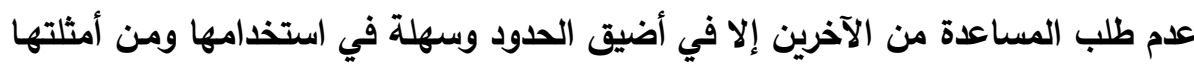
ناطق الجوال لذوي الإعاقة البصرية. ويضيف الباحثان هنا تكنولوجيا مستخدمة كثيرًا خاصة مع ذوي الإعاعة الإقات البسيطة، مثل: صعوبات التعلم، وهي برامج تكرار الحروف والأرقام بحيث يمكن تحميلها على الآيباد والجوال. فوائد استذدام التكنولوجيا الحديثة في التربية الخاصة:

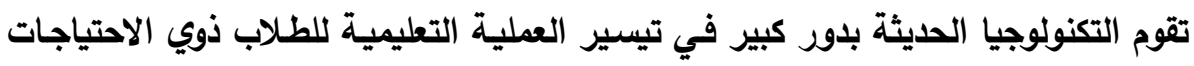

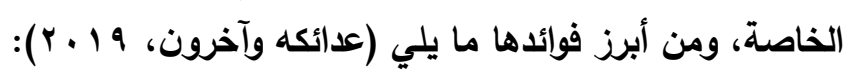

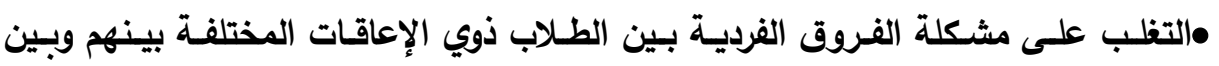

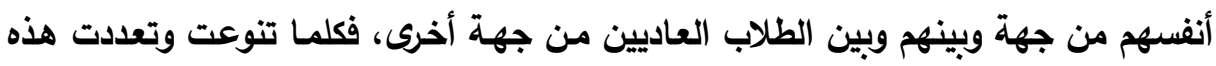
التقنيات الحديثة والتكنولوجية كان ذلك ادين الدعى إلى مراعاة الفروق الفردية. •المساهمة في تكوين اتجاهات مرغوب فيها: حيث تساعد التكنولوجيا التعليمية في تكوين التهان التهات اتجاهات موجبة لاى الأطفال ذوي الاتجاهات الخاصة، مثل: (اتباع النظام والتعاون) مما فيا يساعد الطفل على التكيف الاجتماعي. هتوضيح للمعارف والمعلومـات بطريقـة صحيحة وتناسب قدرات ذوي الإعاقة،على سبيل

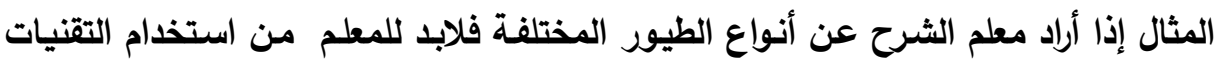

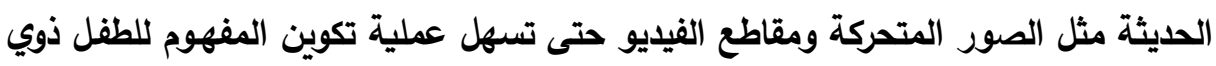
الإعاقة . متعليم وتدريب الأطفال ذوي الإعاقات المختلفة على المهارات الحياتية والأكاديمية اللازمـة

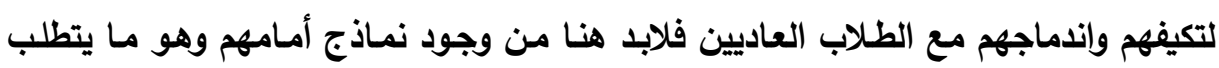
الاستعانة بالتكنولوجيا الحديثة. متساعد هذه التقنيات الحديثة والتكنولوجيا الأطفال ذوي الإعاقة على تجنب عدم ادراك مالكا يكتبون وينطقون من مفاهيم مجردة من خلال توفير نماذج حسية وتقنية أمامهم لزيادة خبراتهم وتنمية قدراتهم.

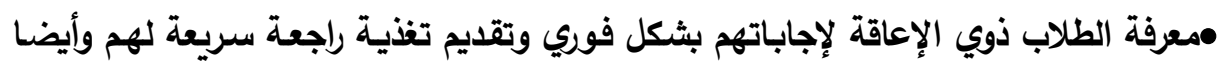
تعزيز الإجابات الصحيحة وتعديل الإجابات الخاطئة في وقتها. 
•ضمان تكرار وإعادة الخبرات الصحيحة وإنتقالها فيمـا بينهم في حالـة تم استخدام هذه التقنيات الحديثة والتكنولوجيا المختلفة وأيضا تثبيت المعلومات .

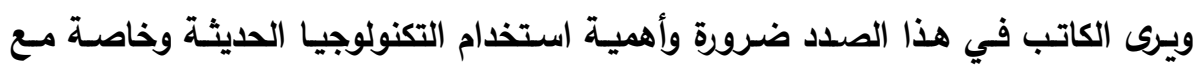
الطلاب ذوي الاحتياجات الخاصة وقد تكون من أهم الأسباب لتعليمهم وتدريسهم و وتقبلهم للمعلم وخاصة الطلاب ذوي صعوبات التعلم.

المعوقات التي قد تواجه مستخدمي التقنيات الحديثة والتكنولوجيا في مجال التربية الخاصة: هناك بعض المعوقات والتي قد تعيق من استخدام التكنولوجيا الحديثة في ميدان التربية

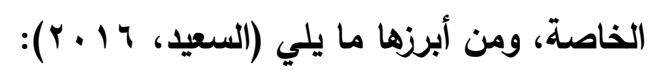

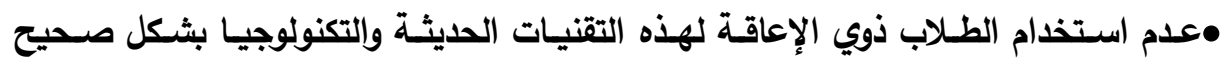
بمفردهم ودون مساعدة المعلم أو أولياء أمورهم. •وجود بعض المشكلات الحسية والجسدية والقصور لديهم ممـا يجعل الاستفادة مـن هذاء أموره التقنيات والتكنولوجيا ضعيف نوعا ما. •توجـه بعض الطلاب ذوي الإعاقـة مـن عدم استخدام هذا التقنيـات الحديثة وإلتكنولوجيـا

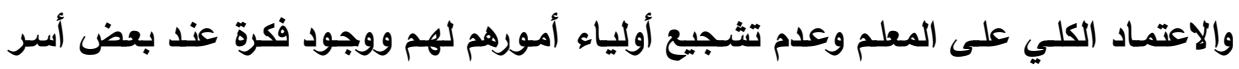
هؤلاء الطلاب لعدم فاعلية هذه التقنيات بسبب إعاقات أبنائهم المعام المختلفة.

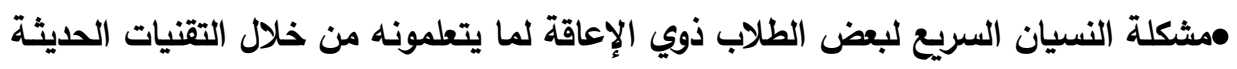
والوسائل التكنولوجية المختلفة. •القصور الإدراكي الحسي أو العقلي للطلاب ذوي الإعاقة قد يحد من استخدام التكنلوجية الحديثة والتقنيات التعليمية بثكل فعال. •النقص في عدد الفنيين وعدم وجودهم في كثير من الأحيان في المدارس أو معاهد وبرامج

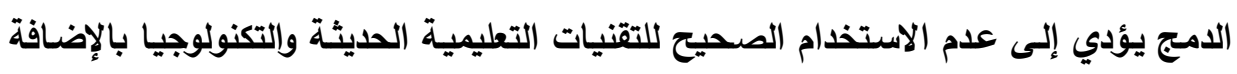

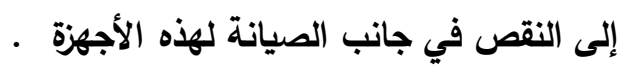
•النقص في هذه الأجهزة والأدوات والتقنيات التعليمية والتكنولوجيا في المدارس والتهن والمعاهد لذوي الإعاقة. •عدم وجود تعليمات وأنثطة في المناهج لذوي الإعاقة تحث على استخدام هذه التقنيات التعليمية والأجهزة التكنلوجية الحديثة. 
• صعوبة تركيب و نقل بعض الأجهزة والتقنيات التكنولوجية الحديثة في غرف المصسادر والفصول العادية الملحق بها بعض الطلاب من ذوي الإعاقة والذين تم دمجهم. •النقص في توفر برمجيات الحاسوب لكل فئة من فئات طلاب التربية الخاصة.

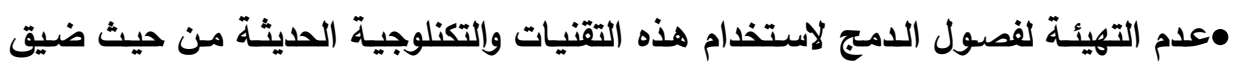
مساحتها في بعض الأحيان. •النقص في وعي أولياء آمور الطلاب ذوي الإعاقة بأهمية استخدام هذه التقنيات الحديثة

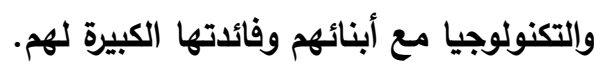
ويرى الباحثان بالإضـافة للمعوقات السـابقة أنسه قد يوجد معوقائهات أخرى تتعلق بـالمعلم، ومنها: عدم توفير التدريب الكافي للمعلمين لاستخدام التكنولوجيا الحديثة في العملية التعليمية لذوي الاحتياجات الخاصة، وأيضًا عدم رغبة بعض المعلمين التولين في تغيير الروتين للعملية التعليمية. ثانيًا: الاراسات السابقة

دراسـة آل حاوي (د.ت) بعنوان " واقع استخدام أعضساء هيئة التدريس والهيئة المسـاندة

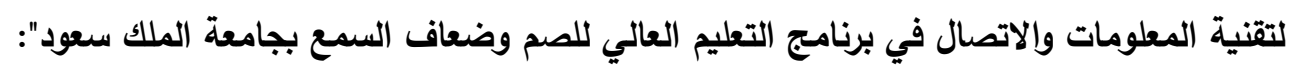
هدف البحث إلى تعريف واقع استخدام أعضاء هيئة التدربس والهيئة المساندة في برنامجاج التعليم العالي للطلاب الصم وضعاف السمع بجامعة الملك سعود لتقنية المعلومات والاتصال.

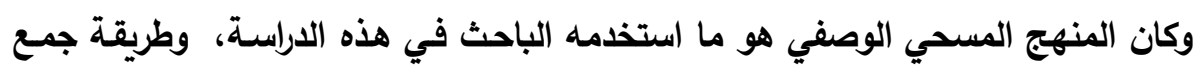

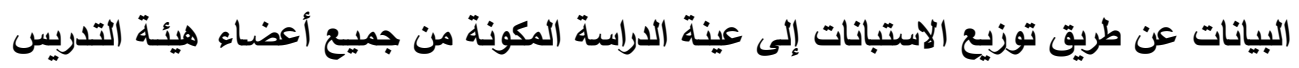

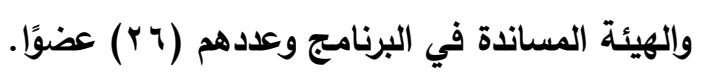

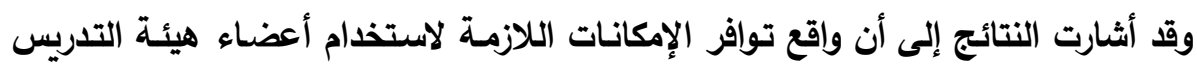

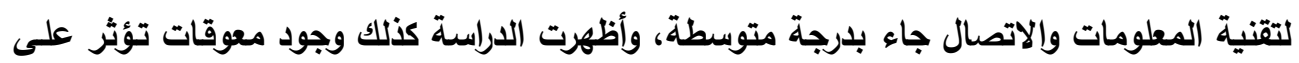
استخدامهم لتقنية المعلومات والاتصال، منها: - ارتفاع التكلفة الاقتصادية لاستخدام تقنية المعلومات والاتصال مقارنة بالتعليم التقليدي.

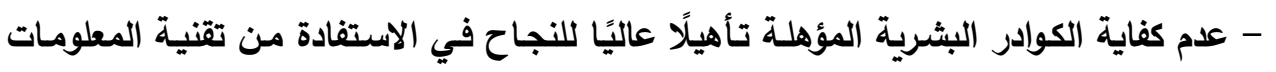

\section{والاتصال وصيانتها.} - التأثيرات السلبية لاستخدام تقنية المعلومات والاتصال في الجوانب المعرفية من خلال قيام الطلاب بالغش في حل الاختبارات والواجبات والتكاليف. - قلة الاهتمام بتدريب أعضاء هيئة التدريس والطلاب على مهارات استخدام الحاسب الآلي. 
ويرى الكاتب بأن هذه الدراسـة ركزت على فئسة مـن فئـات التربية الخاصـة وهم ضعاف

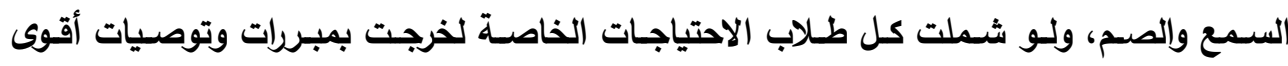

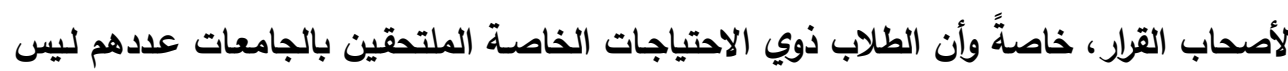
بالكبير - (1)

دراسـة العصيمي (10 • ب) بعنوان: " واقع استخدام التقنيات التعليمية الحديثة في غرفة

المصادر والصعوبات التي يواجها معلمي ذوي صعوبات التعلم في منطقة القصيم":

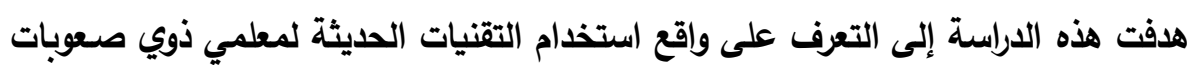
التعلم بمنطقة القصيم وما المعوقات التي قد تواجه المعلمين تجاه استخدام هذه التقنيات.

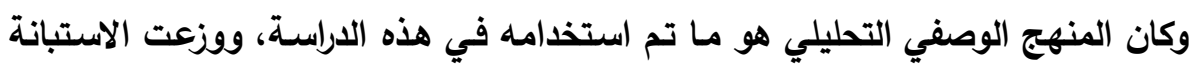

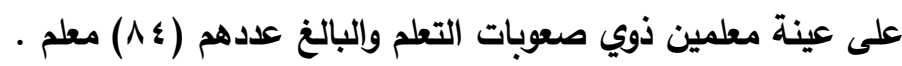

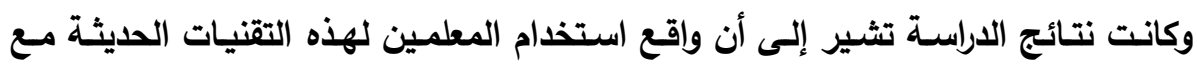

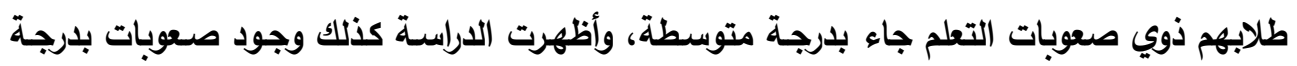

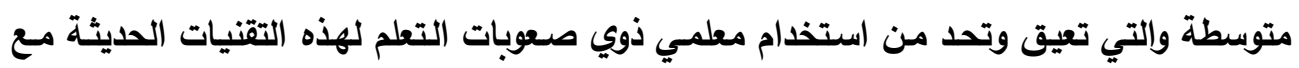
طلابهم. ويرى الكاتب في هذا الثأن أن كون العينة (ء ^) معلمًا قد تكون قليلة، ولا تعطي الدراسـة قيمة كبيرة وواقع فعليا عن المثكلة.

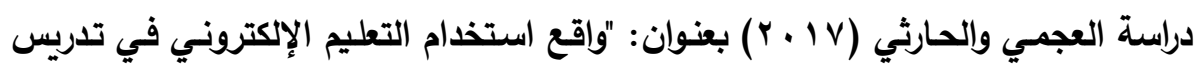
ذوات الإعاقة الفكرية البسيطة في مدارس مدينة الرياض من وجهة نظر المعلمات":

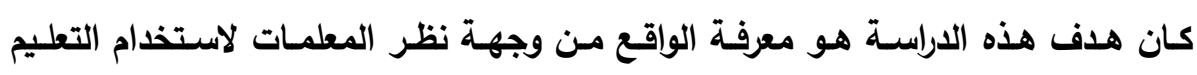
الإكتروني الحديث مع الطالبات ذوي الإعاقة الفكرية البسيطة.

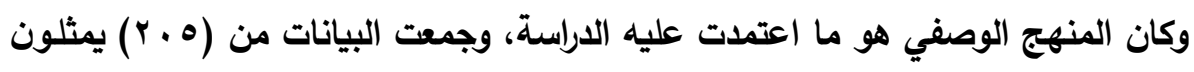

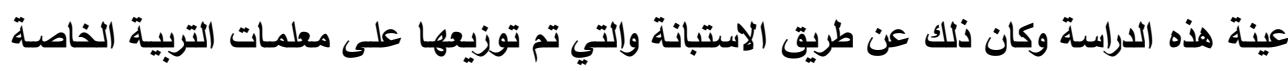

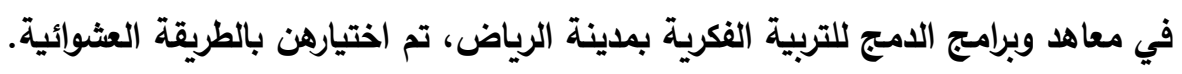

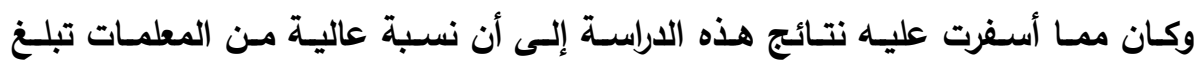

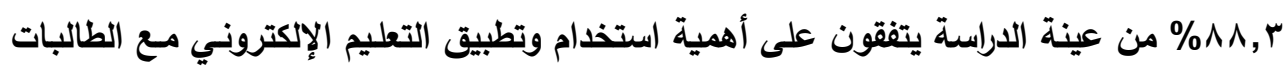

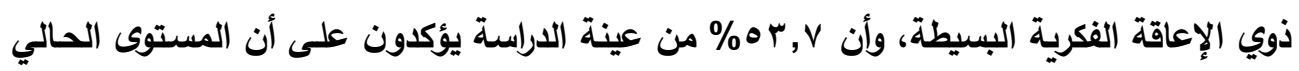
للتعليم الإكتروني في تدريس ذوات الإعاقة الفكرية البسيطة جيد. 
ويرى الباحثان في هذا الصدد أن نسبة عالية تؤيد وترى وجود التعليم الإكتروني ضروري ومهم، وهذا يدل على أهمية استخدام التكنولوجيا في مجال التربية الخاصة.

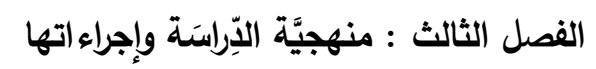
تمهيد:

هدف البحث الحالي إلى التعرُّف على واقع استخدام التكنولوجيا الحديثة في ميدان التربية

$$
\text { الخاصة بالمملكة العزبية السعودية. }
$$

ويتناول هذا الفصل وصف لإجراءات البحث الميدانية التي قام بها الباحثان لتحقيق أهداف

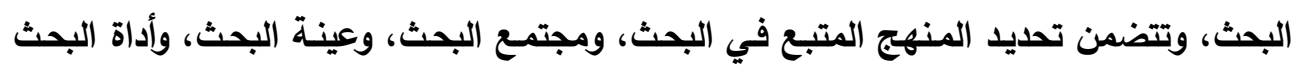

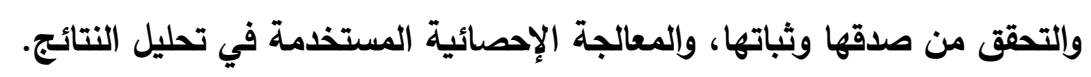

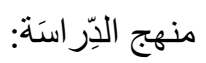

من أجل تحقيق أهداف الدراسـة؛ تم استخدام المنهج الوصفي التحليلي ويعرف المنهج

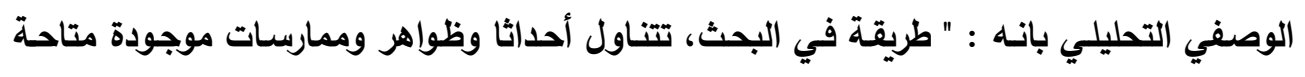

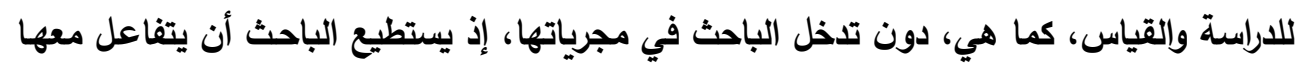

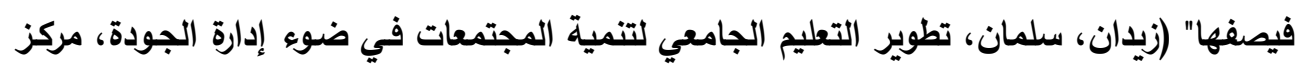

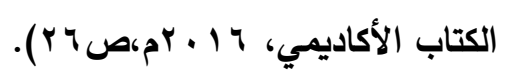
مجتمع البحث وعينته : يتمثل مجتمع البحث في جميع معلمي التربية الخاصة في معهد

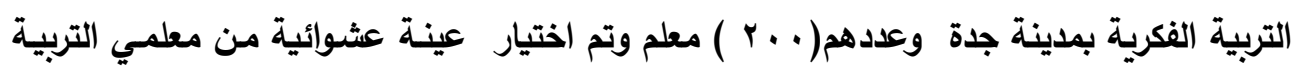
الخاصة وبلغ عددهم ( • ( ) معلم

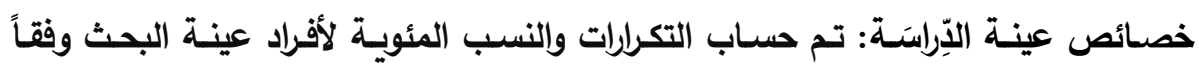
للمتغيرات: •العمر جدول رقم (r- 1 ) توزيع أفراد الآِراسَة وفق متغير العمر

\begin{tabular}{|c|c|c|}
\hline النسبة المئوية & التكرار & العمر العر \\
\hline$r ч, V$ & $\wedge$ & أقل من · r سنة \\
\hline or,r & 17 & من 30 الى ه ؛ سنة \\
\hline$r \cdot, \cdot$ & 7 & أكبر من 0 ؛ سنة \\
\hline$\% 1 \ldots$ & r. & المجموع \\
\hline
\end{tabular}




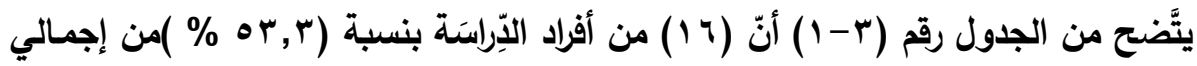

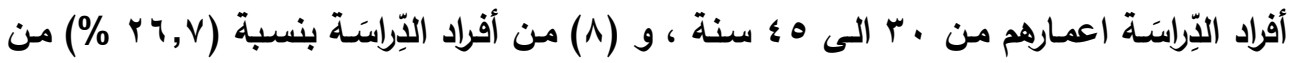

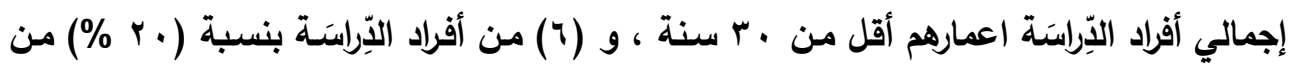

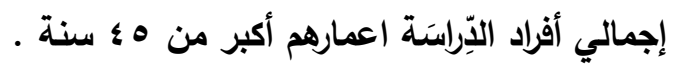
شكل رقم (r-1) توزيع أفراد الآرّاستة وفق متغير العمر

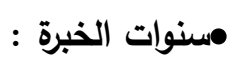

جدول رقم (ץ-ץ) توزيع أفراد الآّراسَة وفق متفير سنوات الخبرة

\begin{tabular}{|c|c|c|}
\hline النسبة المئوية & التكرار & سنوات الخبرة \\
\hline$r_{., .}$. & 7 & اقل من • سنوات \\
\hline ๑.,. & 10 & من 5 إلى . 1 سنوات \\
\hline$r \cdot, \cdot$ & 9 & أكثر من · 1 سنوات \\
\hline$\% 1 \ldots$ & r. & 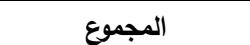 \\
\hline
\end{tabular}

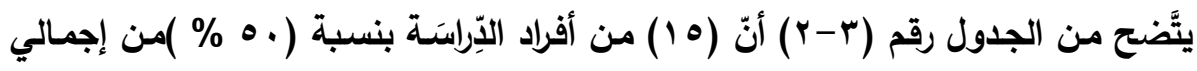

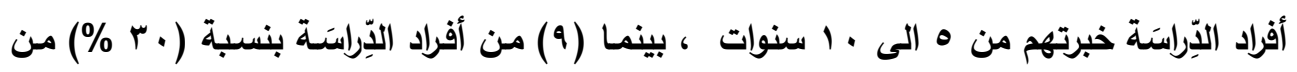

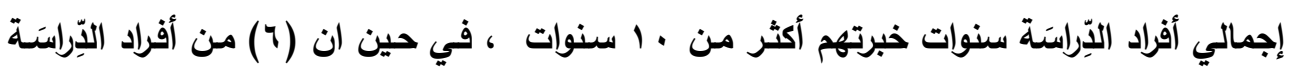

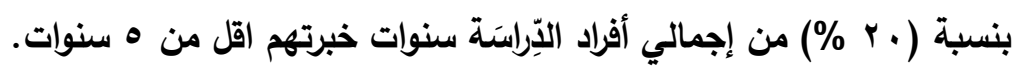

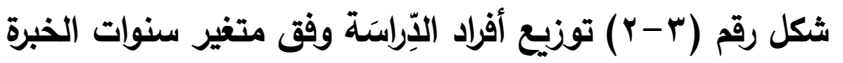

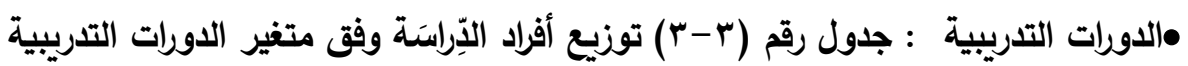

\begin{tabular}{|c|c|c|}
\hline النسبة & التكرار & الدورات التدريبية \\
\hline $1 \mu, r$ & $\varepsilon$ & أقل من r دورات \\
\hline$\Upsilon 4, \mathrm{~V}$ & $r$. & من س-ه دورات \\
\hline r.,. & 1 & أكثر من ه دورات \\
\hline$\% 1 \ldots$ & $r$. & المجموع \\
\hline
\end{tabular}

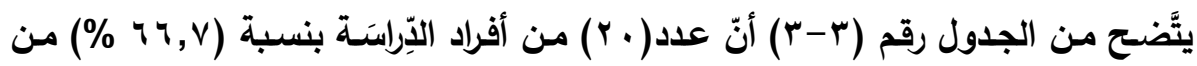

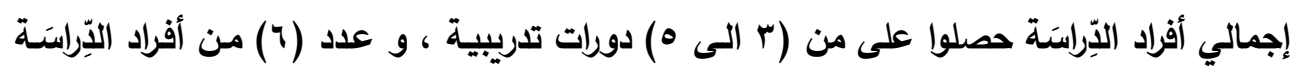

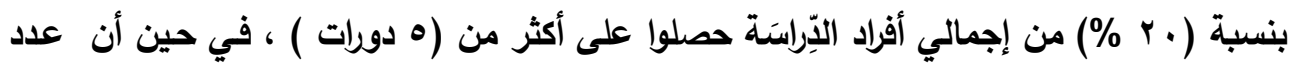

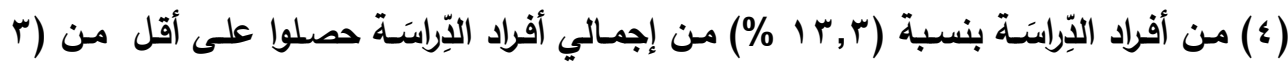


شكل رقم (r-r) توزيع أفراد الآراسَة وفق متغير الدورات التدريبية

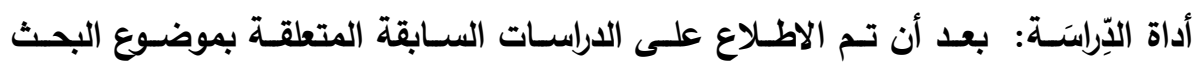

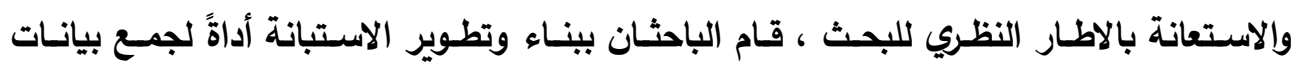

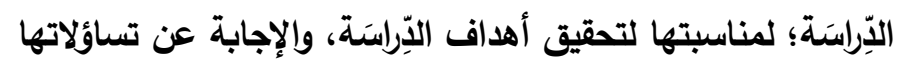

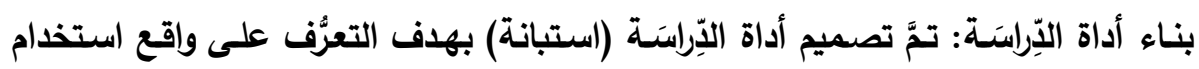

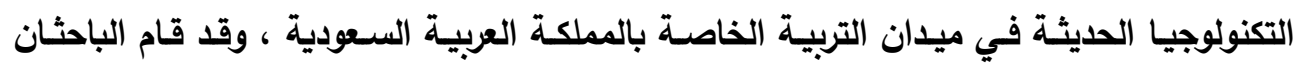

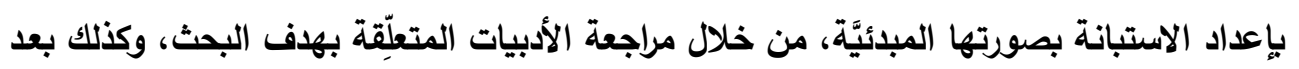

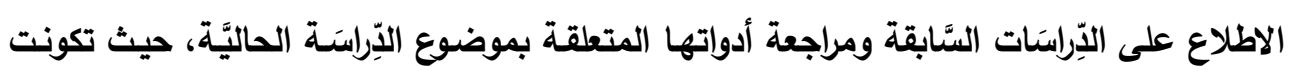

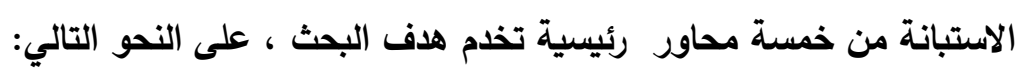

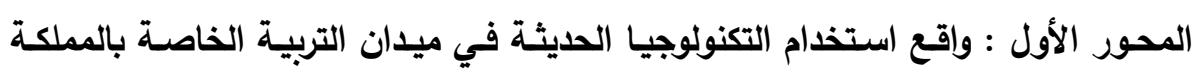
العربية السعودية ويتكون من ^ فقرات الاول وافع الفيتات المحور الثاني : تصنيف التكنولوجيا الحديثة حسب مجالات استخدامها في الحياة لذوي

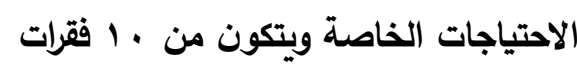
المحور الثالث : فوائد استخدام التكنولوجيا الحديثة في التربية الخاصة ويتكون من ل فقرات المحور الرابع : معوقات استخدام التكنولوجيا الحديثة في ميدان التربية الخاصة ويتكون من · م المقرات المحور الخـامس : دور التكنولوجيا في ظل جائحة كورونـا في تعليم ذوي الاحتياجـات

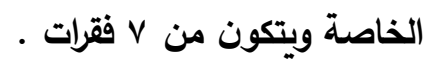
صدق أداة الذِّر اسَة: إن صدق الأداة يعني التأكُّد من أنها سوف تقيس مـا أعدت لقياسـه، كما يُقصد بالصداق

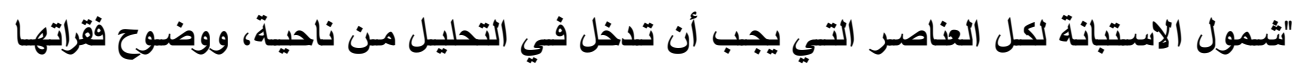

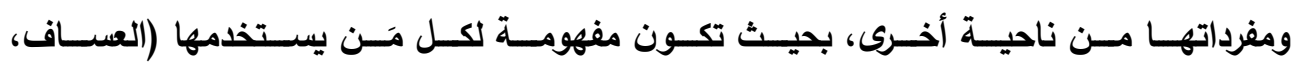

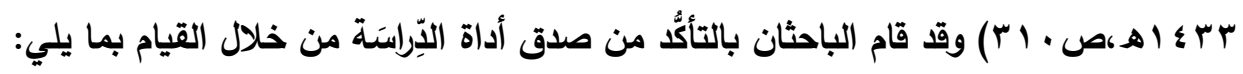
• الصدق الظاهري للأداة (التحكيمي):

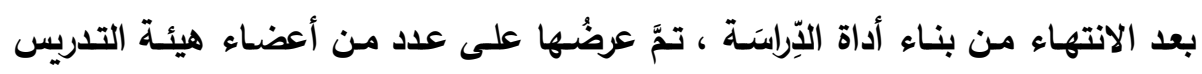

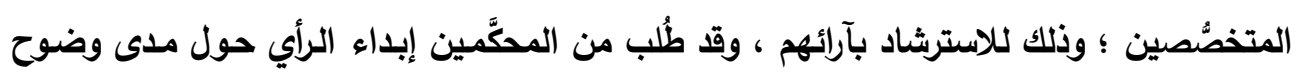


العبارات ، ومدى ملاءمتها لما وُضعت لأجله ، ومدى مناسبة العبارات للمحور الذي تنتمي إليه، مع وضع التعديلات والاقتراحات التي يمكن من خلالها تطوير الاستبانة.

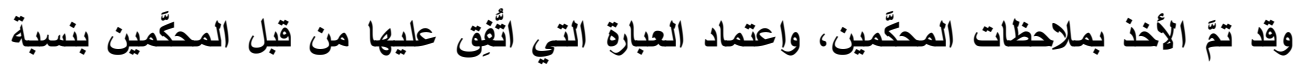

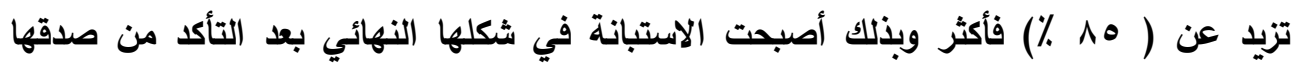
الظاهري مكونة من (0 ؛ ) فقرة مقسمة على خمسة محاور رئيسية

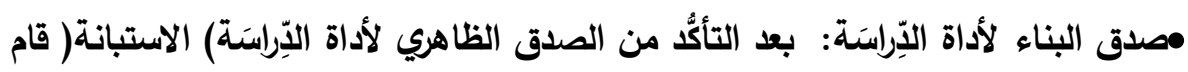

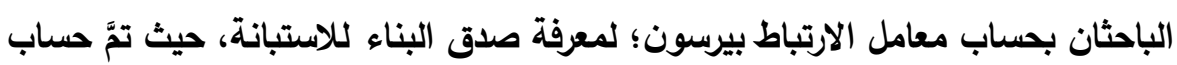

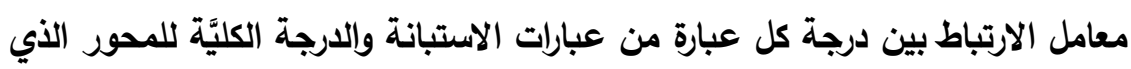

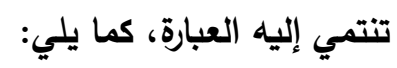
المحور الأول : ما درجة توفر متطلبات تحقيق التمية المهنية لمعلم الأحياء جدول (r- §) معامل ارتباط بيرسون بين كل فقرة والدرجة الكليَّة للمحور الاول

\begin{tabular}{|c|c|c|c|}
\hline معامل ارتباط بيرسون & رقم الفقرة & معامل ارتباط بيرسون & رقم الفقرة \\
\hline$\cdot, \vee \vee \diamond * *$ & 0 & $\cdot, \vee \vee 0 * *$ & 1 \\
\hline$\cdot, 7 \leqslant \Lambda * *$ & 7 & $\cdot, \leqslant \wedge q \% *$ & $r$ \\
\hline •, $\{97 \% *$ & v & $\cdot, \Lambda \cdot \leq * *$ & $r$ \\
\hline , , $\vee \vee \curlyvee \div *$ & $\wedge$ & $\cdot, 9 \cdot 1 * \%$ & $\varepsilon$ \\
\hline
\end{tabular}

**دال عند مستوى دلالة I., ,.

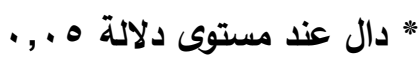
يتَّضـح من الجدول السـابق أن معاملات الارتباط بين الفقرات والارجـة الكليَّة للمحور

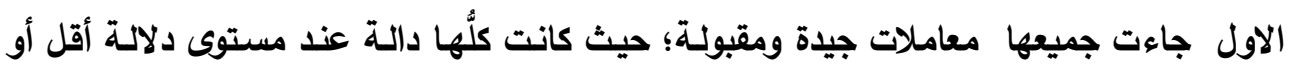
يساوي (0. ., •). المحور الثاني : تصنيف التكنولوجيا الحديثة حسب مجالات استخدامها في الحياة لذوي الاحتياجات الخاصة جدول (r-ه) معامل ارتباط بيرسون بين كل فقرة واللارجة الكليَّة للمحور الثاني

\begin{tabular}{|c|c|c|c|}
\hline معامل ارتباط بيرسون & رقم الفقرة & معامل ارتباط بيرسون & رقم الفقرة \\
\hline$\cdot, \vee \vee \neg * *$ & 1 & $\cdot, \wedge \wedge)^{* *}$ & 1 \\
\hline$\cdot, \Lambda \cdot r^{*} *$ & $v$ & $\cdot, \wedge \wedge 9 \% *$ & r \\
\hline$\cdot, \leqslant \leqslant$, $\% *$ & $\wedge$ & $\cdot, 9 r^{*} * *$ & $r$ \\
\hline
\end{tabular}




\begin{tabular}{|l|c|c|c|}
\hline,, $74 \leqslant * *$ & 9 &.,$\wedge 01 \% *$ & $\varepsilon$ \\
\hline., $0 \wedge 1 \% *$ & 1. &., $7 \vee 0 \% *$ & 0 \\
\hline
\end{tabular}

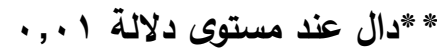

* دال عند مستوى دلالة ه . , .

يتَّضح من الجدول السابق أن معاملات الارتباط بين الفقرات واللارجة الكليَّة للمحور الثاني

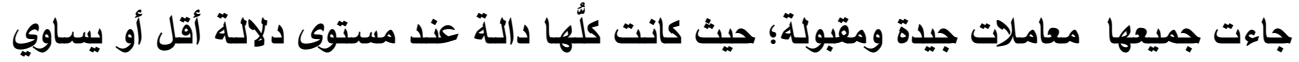
$\cdot(\cdot, \cdot)$

المحور الثالث : فوائد استخدام التكنولوجيا الحديثة في التربية الخاصة.

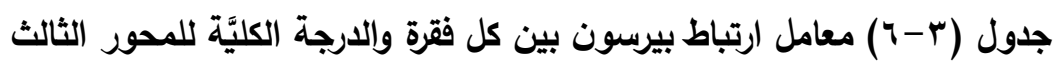

\begin{tabular}{|c|c|c|c|}
\hline معامل ارتباط بيرسون & رقم الفقرة & معامل ارتباط بيرسون & رقم الفقرة \\
\hline$\cdot, \vee \cdot \Delta * *$ & 1 & $\cdot, \wedge \cdot 1 \% *$ & 1 \\
\hline 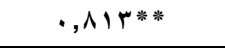 & v & $•, \vee ৭ . * \%$ & $r$ \\
\hline •, フ $9 \% *$ & $\wedge$ & •, $V \Psi \leq * \%$ & $r$ \\
\hline$\cdot, \wedge \leq 1 \%$ & 9 &.,$\circ \curlyvee \wedge * *$ & $\varepsilon$ \\
\hline •,А^ץ\%* & 1. & $\cdot, 719 \% *$ & 0 \\
\hline
\end{tabular}

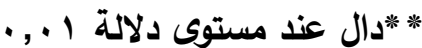
* دال عند مستوى دلالة ه ., .

يتَّتح من الجدول السابق أن معاملات الارتباط بين الفقرات والدرجة الكليَّة للمحور الثالث

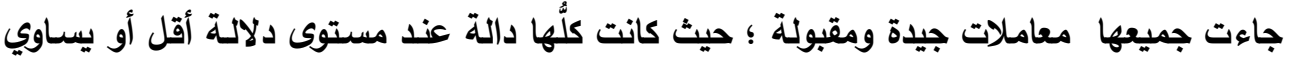
$\cdot(\cdot, \cdot 0)$

المحور الرابع : معوقات استخدام التكنولوجيا الحديثة في ميدان التربية الخاصة. جدول (Y-r) معامل ارتباط بيرسون بين كل فقرة والدرجة الكليَّة للمحور الرابع

\begin{tabular}{|c|c|c|c|}
\hline معامل ارتباط بيرسون & رقم الفقرة & معامل ارتباط بيرسون & رقم الفقرة \\
\hline •, イノ & 1 & •, $9 r \mu * *$ & 1 \\
\hline$\cdot, \diamond \diamond \wedge * \%$ & $v$ & •, $\mathrm{V} \varepsilon$, ** & $r$ \\
\hline ., $\vee ৭ \curlyvee * *$ & $\wedge$ & 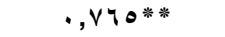 & $r$ \\
\hline$\cdot, \vee \vee \wedge * *$ & 9 & ., $70 \leqslant * *$ & $\varepsilon$ \\
\hline$\cdot, \nearrow \leq 1 * *$ & 1. & ., $\vee Y Y * *$ & 。 \\
\hline
\end{tabular}

** دال عند مستوى دلالة ا +,. * دال عند مستوى دلالة ه.., . 
يتَّضح من الجدول السابق أن معاملات الارتباط بين الفقرات واللارجـة الكليَّة للمحور الرابع

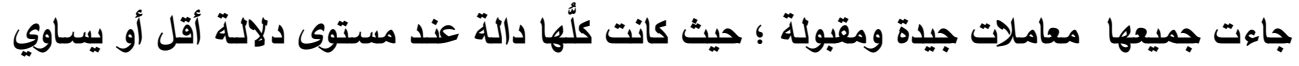

$$
\cdot(\cdot, \cdot 0)
$$

المحور الخامس : دور التكنولوجيا في ظل جائحة كورونا في تعليم ذوي الاحتياجات الخاصة .

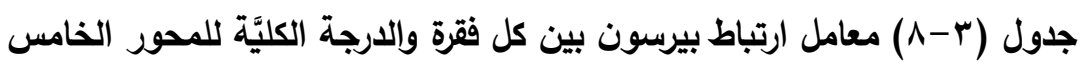

\begin{tabular}{|c|c|c|c|}
\hline معامل ارتباط بيرسون & رقم الفقرة & معامل ارتباط بيرسون & رقم الفقرة \\
\hline$\cdot, \diamond \wedge £ * *$ & ○ & $\bullet, \wedge \curlyvee . * *$ & 1 \\
\hline •, $\vee Y Y * *$ & 1 & •, Я Yr** & r \\
\hline$\cdot, \wedge \cdot 9 * *$ & v & •, §ヘฯ\%* & $r$ \\
\hline & & $\cdot, \wedge 1 . * * *$ & $\varepsilon$ \\
\hline
\end{tabular}

$$
\begin{aligned}
& \text { ** دال عند مستوى دلالة ا +, , } \\
& \text { * دال عند مستوى دلالة ه ., . }
\end{aligned}
$$

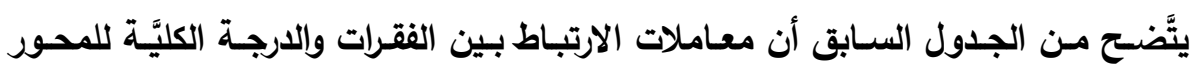

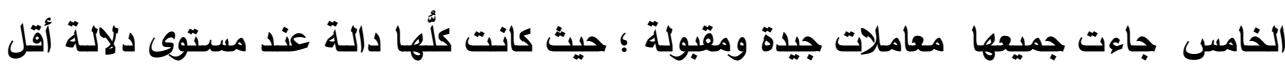

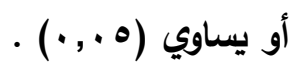

ثبات أداة الإِراسسَة:

تمَّ التأكُّد من ثبات أداة الآِراسَة باستخدام معادلة (ألفا كرونباخ Cronbach'a Alpha)

\begin{tabular}{|c|c|}
\hline $\begin{array}{l}\text { معامل الثبات بطريقة ألفا } \\
\text { كرونباخ }\end{array}$ & محاور الاستبانة \\
\hline$\cdot, \wedge \circ \wedge$ & المعربة الأول : واقع استخدام التكنولوجيا الحديثة في ميدان التربية الخاصة بالمملكة \\
\hline$\cdot, \wedge \wedge r$ & الاحتياجات الخاصة الثاني : تصنيف التكنولوجيا الدايثة حسب مجالات استخدامها في الحياة لذوي \\
\hline$\cdot, \mathrm{V} r \mathrm{q}$ & المحور الثالث : فوائد استخدام التكنولوجيا الحديثة في التربية الخاصة \\
\hline$\cdot, \wedge \wedge r$ & المحور الرابع : معوقات استخدام التكنولوجيا الحديثة في ميدان التربية الخاصة \\
\hline$\cdot, v \leq 0$ & الخحور الخامس : دور التكنولوجيا في ظل جائحة كورونا في تعليم ذوي الاحتياجات \\
\hline
\end{tabular}
وذلك بعد تطبيقها على عينة الإّراسَة، والجدول التالي يوضح معاملات الثبات الثبات حسب معادلة ألفاد

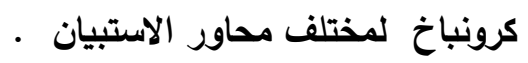

جدول(r- - ج) قيم معاملات الثبات حسب معادلة ألفا كرونباخ لمختلف محاور أداة الدّراسَة 


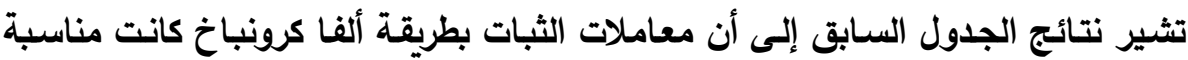
لأغراض البحث العلمي؛ حيث تثير نتائج الجدول السابق إلى ارتفاع معاملات الثبات بطريقة ألفا

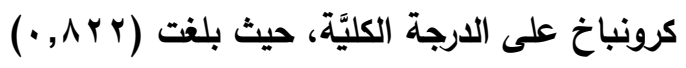

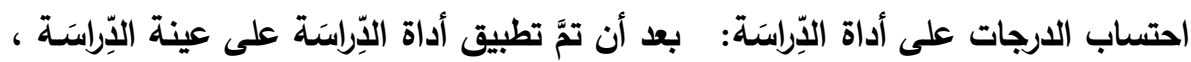

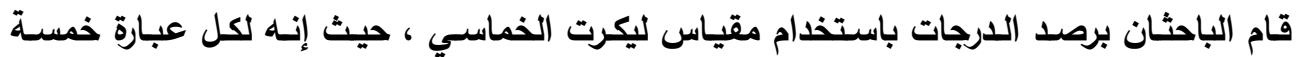

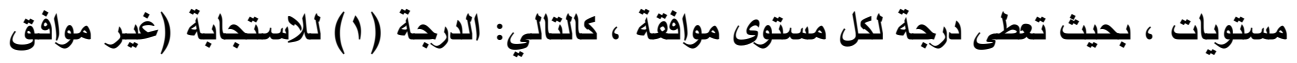

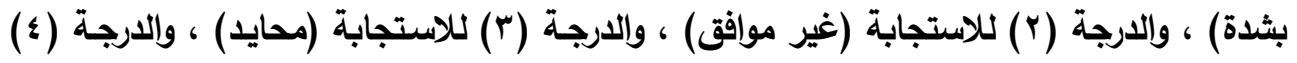

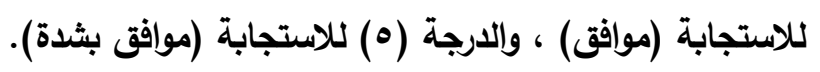
أسـاليب تحليل البيانـات: استخدم الباحثان لتحليل بيانـات الآّراسَسة ومعالجتها إحصائيًا البرنامج الإحصائي(Spss) Statistical Package for Social Sciences (الحزم الإحصائيَّة

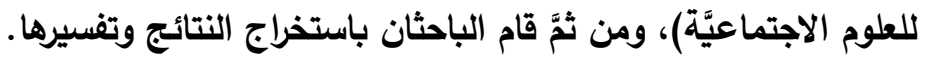

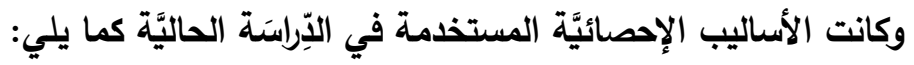

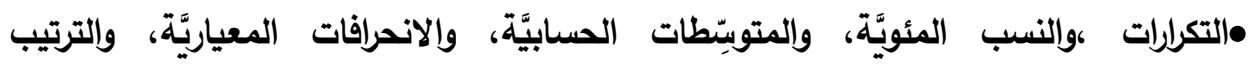

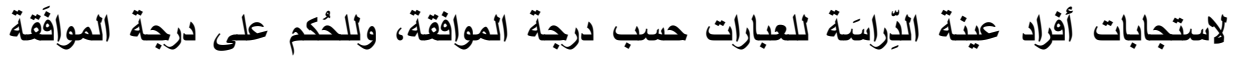

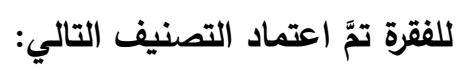

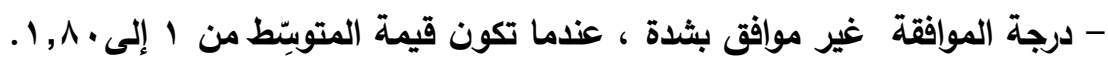

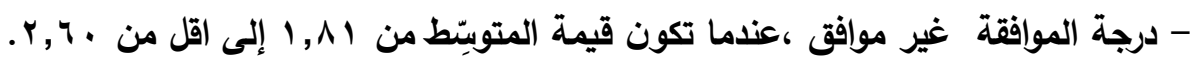

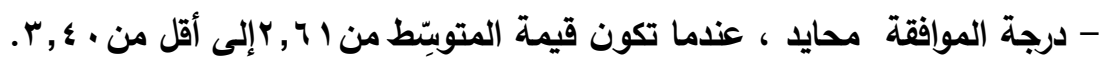

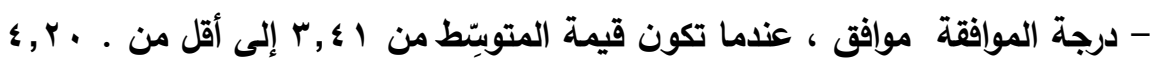

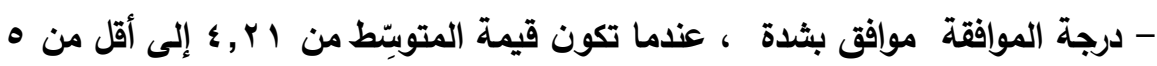
مدعادلة ألفا كرونباخ، للتحقُق من ثبات أداة الآّراسَة.

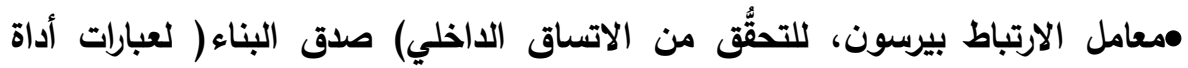
الأِراسَة.

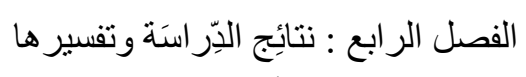

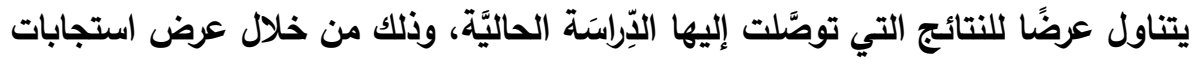

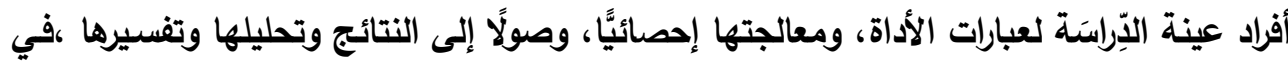


ضوء الأطر النظريَّة، والَّدراسَـات السـابقة المتعلقـة بموضوع الاراسـة ، ويقوم الباحثان بمناقشـة النتائج التي توصلت إليها الإّراسَة وتفسيرها، من خلال الإجابة عن أسئلتها.

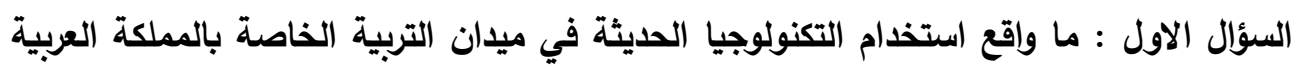
السعودية؟

للتعرف على واقع استخدام التكنولوجيا الحديثة في ميدان التربية الخاصة بالمملكة العربية

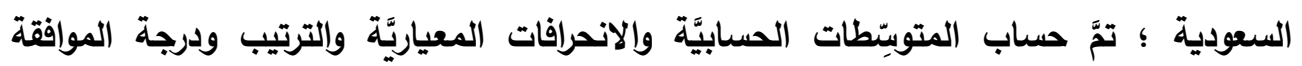
لفقرات المحور الأول للاراسة كما يلي :

جدول) \& - 1)(المتوبِّطات الحسابيَّة والانحرافات المعياريَّة والترتيب لعبارات المحور الاول

\begin{tabular}{|c|c|c|c|c|}
\hline 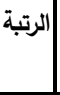 & 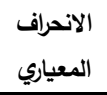 & المتوسط & الفقرة & رقفم \\
\hline$\varepsilon$ & vч०. & $\varepsilon, \cdot r$ & يعتبر استخدام التكنولوجيا الحديثة من الحلول الإبداعية المبتكرة لمشكلات التعليم & 1 \\
\hline 1 & 7.4. & $\varepsilon, 4 V$ & التعليمي بشكل يسامد التكنولوجيا الحديثة في ميدان التربية الخاصة في إعادة صياغة وتصميم المحتوى & r \\
\hline 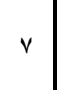 & $1,1.4$ & $\hookrightarrow, \wedge \vee$ & والمصادر التعليمية والبرمجيات التكولوجيا الدايثة في ميدان التربية الخاصة في توفير الأجهزة والمواد واللوسائل & $r$ \\
\hline$\wedge$ & $1, \cdot r$. & $r, \wedge r$ & الخاصتخدم التكنولوجيا الحديثة في علاج كثير من المشكلات السلوكية والنفسية لذوى الاحتياجات & $\varepsilon$ \\
\hline 1 & $1,1 \times 9$ & $r, 9 \vee$ & تستخدم التكنولوجيا الحديثة في تحسين النطق والكلام للأطفال المعاقين & $\bullet$ \\
\hline r & $\vee \vee \varepsilon$. & $\varepsilon, r$ & تساعد التكنولوجيا الحديثة في تبادل الخبرات والمعلومات بين ذوى الاحتياجات الخاصة & 1 \\
\hline$r$ & צr. & $\varepsilon, 1$. & تساعد تقنيات التكنولوجيا الحديثة في خروج ذوى الاحتياجات الخاصة من العزلة والانطوائية & v \\
\hline • & ৩१. & $\varepsilon, \cdot r$ & الاحتياجات الخاصدة التكنولوجيا الحديثة في تنمية روح العمل الجماعي وحب المشاركة بين طلاب ذوى & $\wedge$ \\
\hline & $\cdot, \wedge \bullet$ & $\varepsilon, .9$ & المتوسط العام & \\
\hline
\end{tabular}

يتبين من الجدول السابق أن واقع استخدام التكنولوجيا الحديثة في ميدان التربية الخاصـة

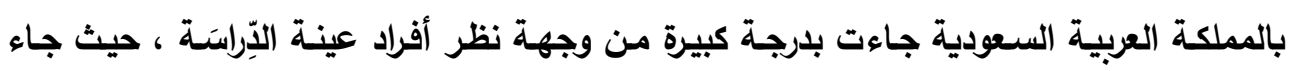




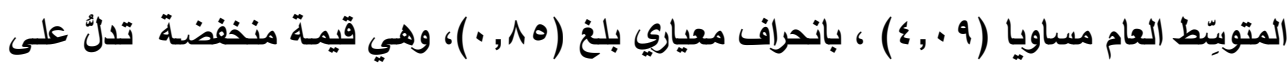

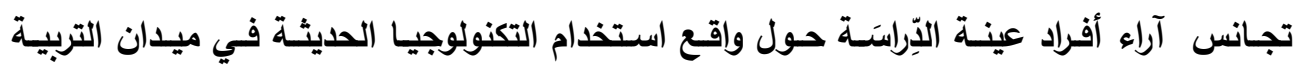

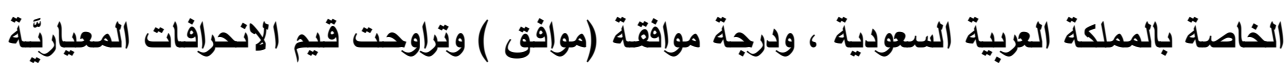

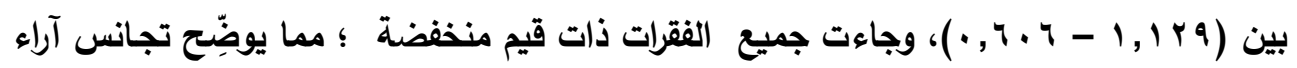

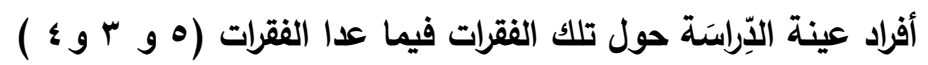

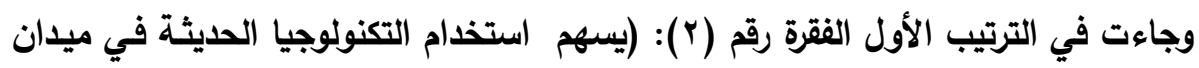
التربية الخاصـة في إعادة صياغة وتصميم المحتوى التعليمي بثكل يساعد في الحصول على الاولى

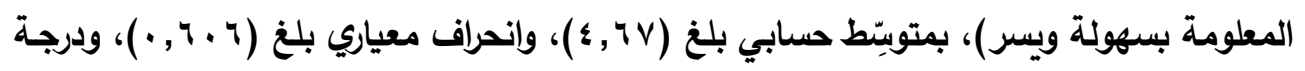

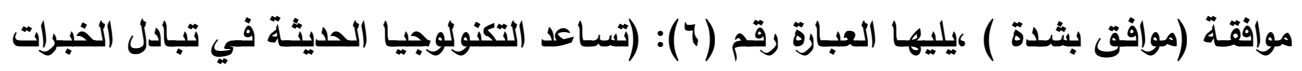

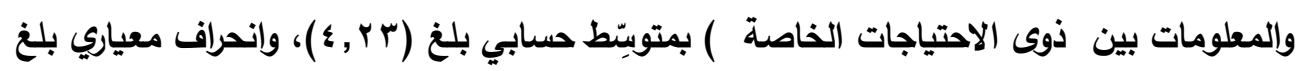

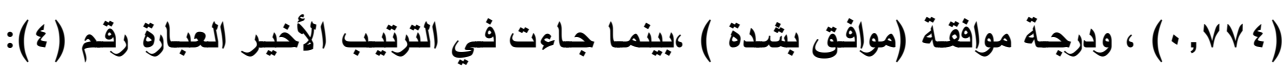

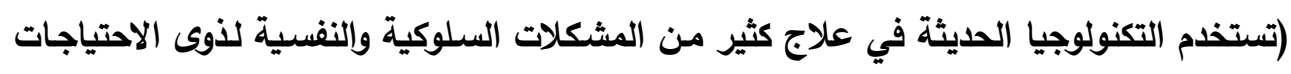

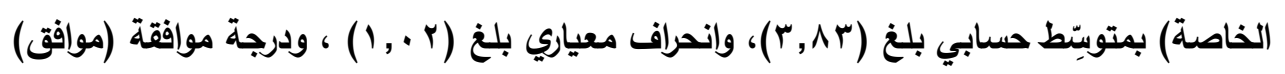

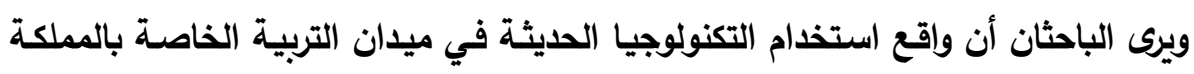

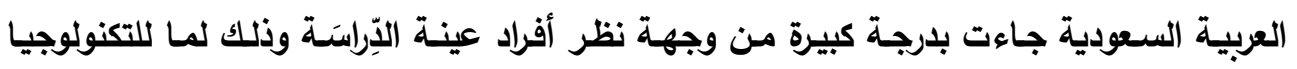
دور كبير في ميدان التربية الخاصة حيث تسهم التكنولوجيا في إعادة صياغة وتصميم المحتوى ونطي

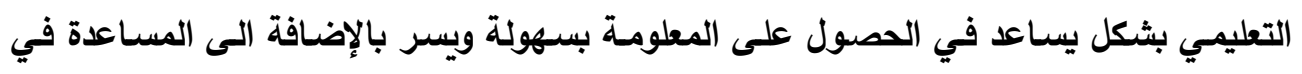

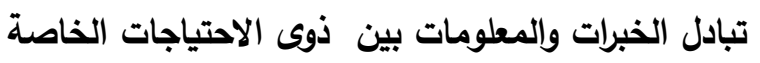

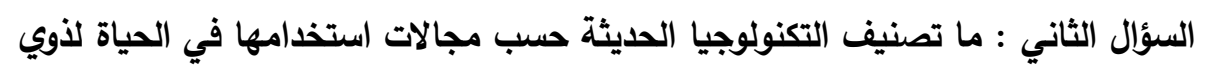

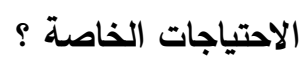
للتعرف على تصنيف التكنولوجيا الحديثة حسب مجالات استخدامها في الحياة لذوي

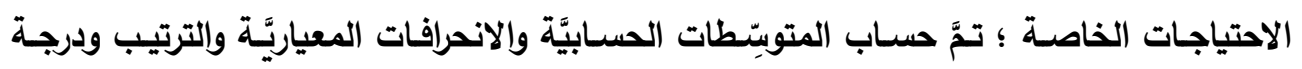

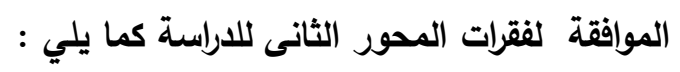

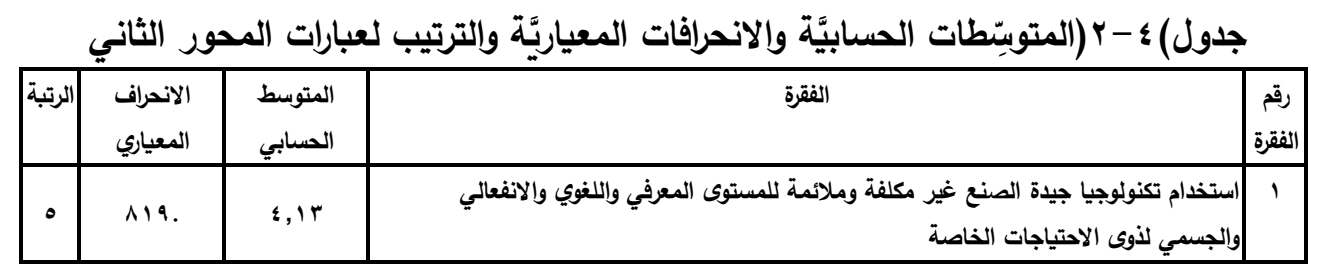




\begin{tabular}{|c|c|c|c|c|}
\hline $\mathrm{v}$ & $1, \cdot r r$ & $\varepsilon, \cdot r$ & |ستخدام تكنولوجيا ملائمة لفئة الإعاقة المراد تعليمها. & r \\
\hline$r$ & $74 \leq$. & $\varepsilon, r$. & 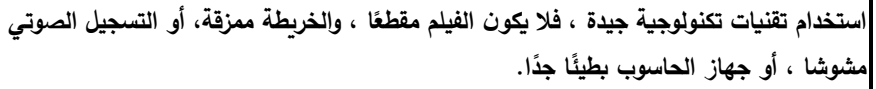 & $r$ \\
\hline r & ४⿻ч. & $\varepsilon, r_{1}$ & استخذام التقنيات الاكترونية و غير الإكترونية منها الصعب والسهل والمتوسط & $\varepsilon$ \\
\hline 1 & \1. & $\varepsilon, \varepsilon V$ & استخدام التكنولوجيا النابعة من المنهج المدرسي. & - \\
\hline$\wedge$ & $9 \ldots$ & $r, \wedge v$ & استخدام التكنولوجيا التي تساعد في تحقيق الأهداف العامة والخاصة للارس. & 1 \\
\hline$\varepsilon$ & 90. & $\varepsilon, 1 \vee$ & استخدام التكنولوجيا التي تكون مناسبة لمستوى التلاميذ. & $\mathrm{v}$ \\
\hline 1 & $\wedge \leq 0$. & $\varepsilon, 1$. & |استخام التكنولوجيا التي تحتوي على عنصر التشويق والجذب وتثير الانتباه والدافعية لاى & $\wedge$ \\
\hline 9 & $1, \cdot v \leq$ & $r, \wedge \vee$ & استخدام تكنولوجيا سهلة وبسيطة وواضحة في عرض المعلومة بدون تعقيد. & 9 \\
\hline 1. & $1, r \leq 0$ & $r, r v$ & |ستخام التقنيات التي تتسم بمرونة الاستخدام وقابلية التعديل والتطوير & 1. \\
\hline & , ^ & $£, ., \varepsilon$ & المتوسط العام & \\
\hline
\end{tabular}

يتبين من الجدول السابق أن تصنيف التكنولوجيا الحديثة حسب مجالات استخدامها في

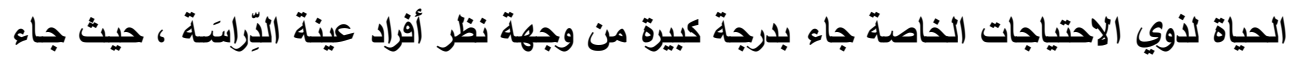

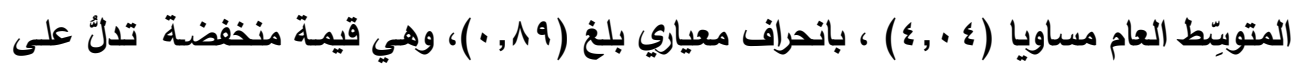

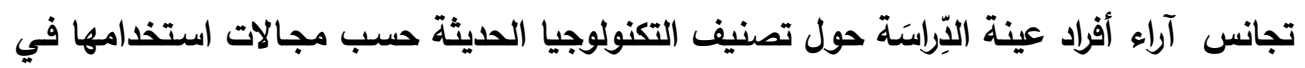

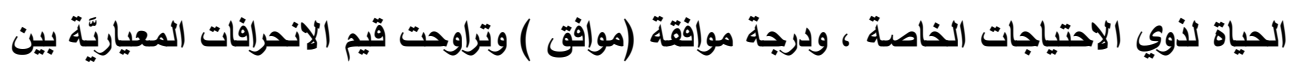

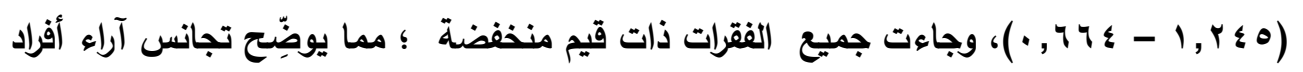

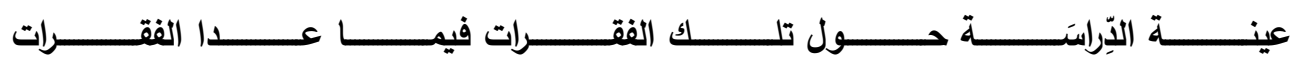
. ( ) ( $1 \cdot)$

وجـاءت في الترتيب الأول الفقرة رقم (ه): (استخدام التكنولوجيـا النابعة مسن المـنهج

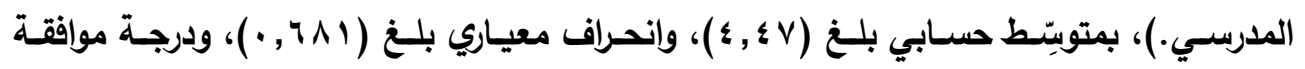

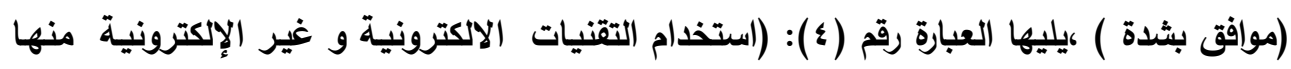

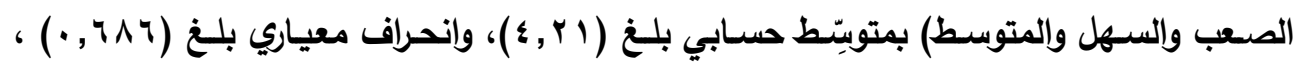

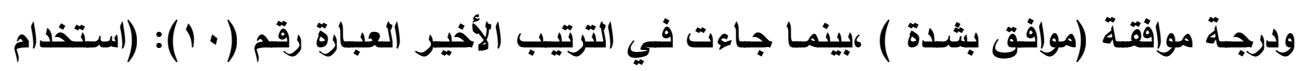

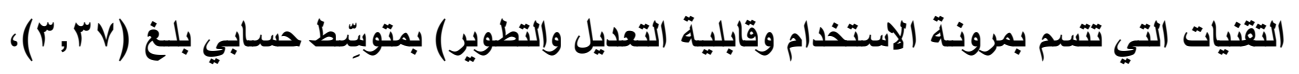
وانحراف معياري بلغ (0 ؛ ب , 1) ، ودرجة موافقة (محايد).

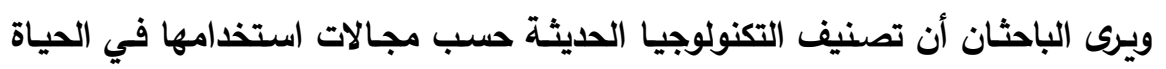

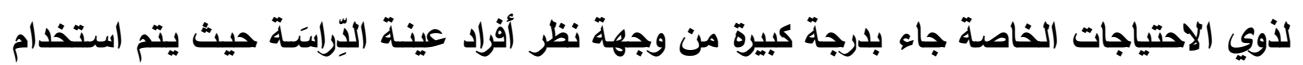

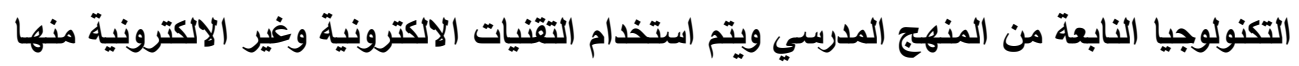


الصعب والسهل والمتوسط حيث يتم استخدام تقنيات تكنولوجية جيدة التي تكون مناسبة لمستوى التلاميذ.

السؤال الثالث : ما فوائد استخدام التكنولوجيا الحديثة في التربية الخاصة ؟

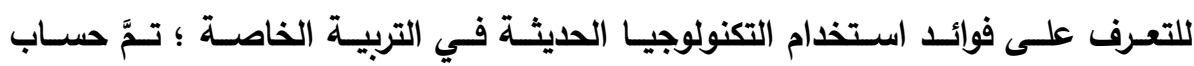

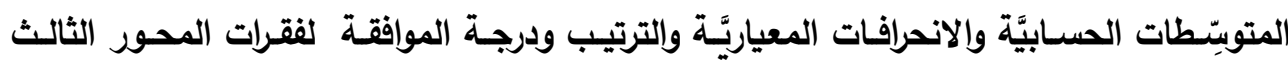
للاراسة كما يلي :

جدول) ؛ - ب(المتوبِّطات الحسابيَّة والانحرافات المعياريَّة والترتيب لعبارات المحور الثالث

\begin{tabular}{|c|c|c|c|c|}
\hline الرتبة & 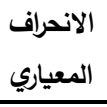 & المستوسط & الفقرة & رقفرة \\
\hline$r$ & $1, .71$ & r & |دون استقلاعهد استخدم التكنولوجيا الحديثة في التغلب على كثير من العقبات التي تحول & 1 \\
\hline 1. & $1,1 \vee 9$ & $r, \Lambda$. & |الاحتياجات الخاصلة التكولوجيا الحديثة على تيسر عملية التواصل الاجتماعي بين التلاميذ ذوى & r \\
\hline 9 & $1, \cdot v_{0}$ & $r, q V$ & |الحياة اليومية. & $r$ \\
\hline$r$ & $\Lambda, r \cdot \Lambda$ & $\varepsilon, \mu$. & |التلاميذ ذوى الاحتياجات الخاصة الوسائل التعليمية الحديثة لها دور كبير في خفض التوتر لاى & $\varepsilon$ \\
\hline$\varepsilon$ & $1,1 \wedge 4$ & $\varepsilon, r$. & للتتلاميذ ذوي الاحتياجات التعليمية الحديثة لها دور في علاج كثير من المشكلات السلوكية والنفسية & 0 \\
\hline 7 & $1, r q \wedge$ & $\varepsilon, 1$. & 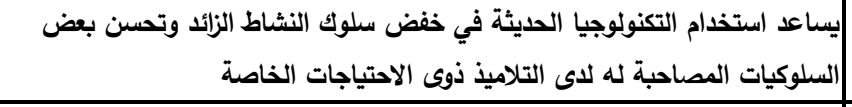 & 7 \\
\hline$\wedge$ & $1, r \wedge \vee$ & $\varepsilon, \ldots$ & |تخهم التكنولوجيا الحيثة في علاج مشكلة الفروق الفردية بين ذوي الاحتياجات & $v$ \\
\hline 0 & $1, r \leqslant r$ & $\varepsilon, 11$ & |تكوئدي تنويع استخدام وسائل تكنولوجيا التعليم المقدمة لذوي الاحتياجات الخاصة إلى & $\wedge$ \\
\hline
\end{tabular}




\begin{tabular}{|c|c|c|c|c|}
\hline v & $1,1 \leqslant r$ & $\varepsilon, \cdot v$ & | وكتابتهم للألفاظ دون إدراك مدلولهائل التكولويا ذوي الاحتياجات الخاصة على تجنب نطقهم & 9 \\
\hline 1 & $1, r \leqslant 1$ & $\varepsilon, r \wedge$ & | يساعد استخدام وسائل التكنولوجيا في نمو جميع المهارات (العقلية والاجتماعية & 1. \\
\hline & $1, r$. & 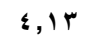 & المتوسط العام & \\
\hline
\end{tabular}

يتبين من الجدول السابق أن فوائد استخدام التكنولوجيا الحديثة في التربية الخاصة جاءت

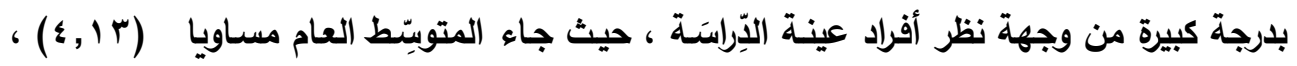

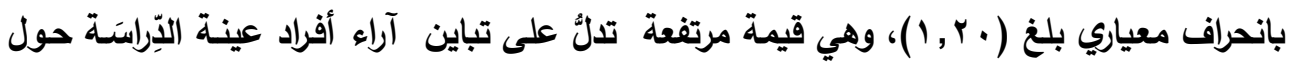

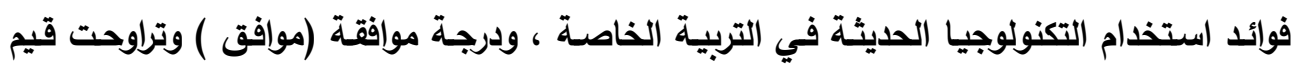

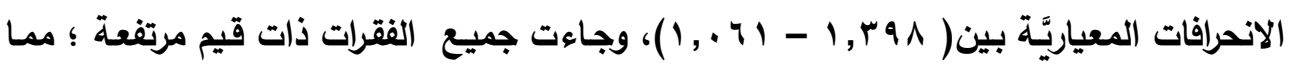

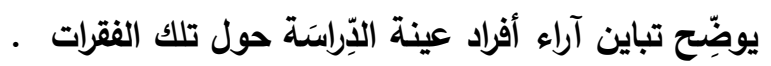

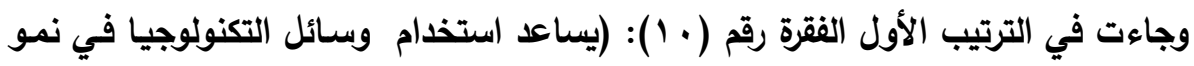

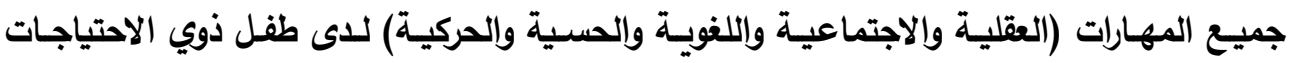

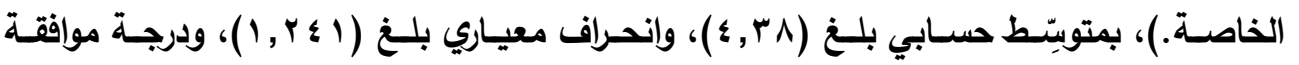

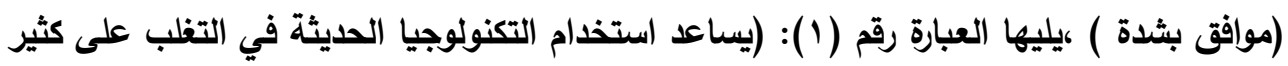

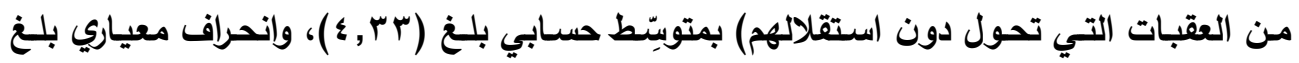

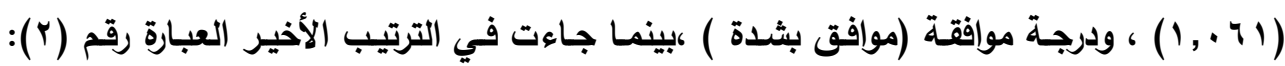
(تعمل التكنولوجيا الحديثة على تيسر عملية التواصل الاجتماعي بين التلاميذ ذوى الاحتياجـات

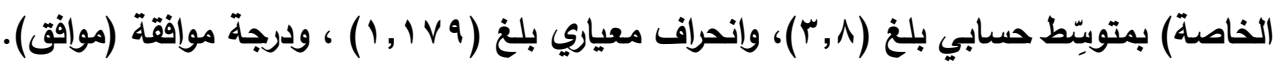

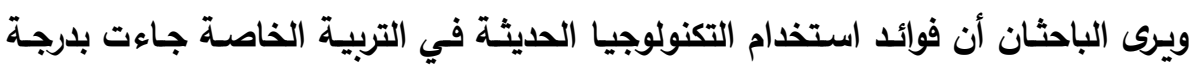
كبيرة من وجهة نظر أفراد عينة التِّراسَة حيث ساعد استخدام وسـائل التكنولوجيا في نمو جميع المهارات (العقلية والاجتماعية واللغوية والحسية والحركية) لدى طفل ذوي الاحتياجات الخاصـة و و تساعد في التغلب على كثير من العقبات التي تحول دون استقلالهم. السؤال الرابع: ما معوقات استخدام التكنولوجيا الحديثة في ميدان التربية الخاصة ؟

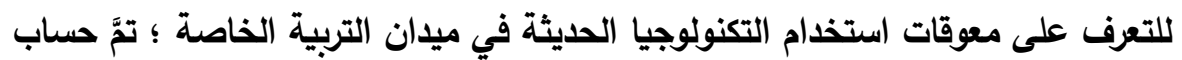

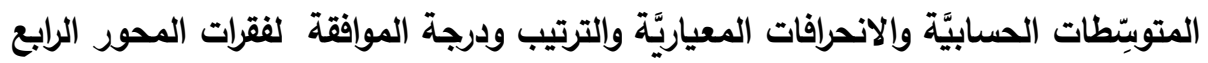

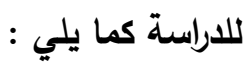

جدول) ؛ - ؛ (المتوبيّطات الحسابيَّة والانحرافات المعياريَّة والترتيب لعبارات البعد الرابع 


\begin{tabular}{|c|c|c|c|c|}
\hline | الرتبة & 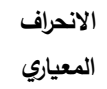 & المستبط & الفقرة & الفقرة - مقم \\
\hline$\wedge$ & $1, r \leqslant 0$ & T,9V & |عدم تأهيل معلمي التربية الخاصة بشكل كاف لاستخدام الوسيلة التعليمية & 1 \\
\hline$\varepsilon$ & 1,YrT & $\varepsilon, r \mu$ & |التدريب بالطريقة العادية التربية الخاصة أن استخام الوسائل التعليمية يحتاج إلى مجهود أكبر من & r \\
\hline 0 & $1, r 10$ & $\varepsilon, r$. & |اعتقاد معلمي التربية الخاصة عدم جدوى الوسائل التعليمية في تعليمهم. & $r$ \\
\hline 9 & irv. & r,9५ & 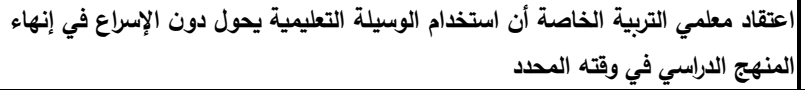 & $\varepsilon$ \\
\hline r & ৩०ᄉ. & 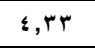 & سوء استخدام التلاميذ من ذوي الاحتياجات الخاصة للأجهزة عذد استخدامهم لها وحدهم. & 。 \\
\hline$r$ & $\wedge \wedge \leq$. & $\varepsilon, r \varphi$ & |قدرتهم على استخدام الوسيلة التعليمية. أو بنية لاى التلاميذ من ذوي الاحتياجات الخاصة والتي تحد من & 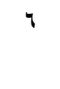 \\
\hline$v$ & $1, \cdot 1 \mathrm{~V}$ & $\varepsilon, \ldots$ & |عدم وجود فني لتشغيل وصيانة الأجهزة التعليمية بالمدرسة & $\mathrm{v}$ \\
\hline 1 & IVO. & . & |عدم توافر أجهزة وأدوات و وسائل تعليمية كافية بالمدرسة & $\wedge$ \\
\hline 1 & ११४. & $\varepsilon, r$. & |خلو الكتب الدراسية من التوجيهات التي تؤكد ضرورة استخدام الوسائل التعليمية. & 9 \\
\hline 1. & $1, r \leqslant r$ & $r, q$. & |صعوبة نقل بعض الأجهزة التكنولوجية إلى الفصول الدراسية. & 1. \\
\hline & -,99 & $\varepsilon, 10$ & المتوسط العام العام & \\
\hline
\end{tabular}

يتبين مسن الجدول السـابق أن معوقات استخدام التكنولوجيا الحديثة في ميدان التربية

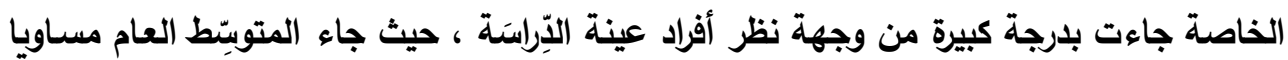

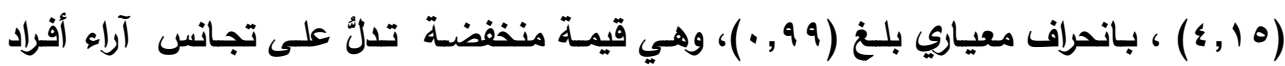

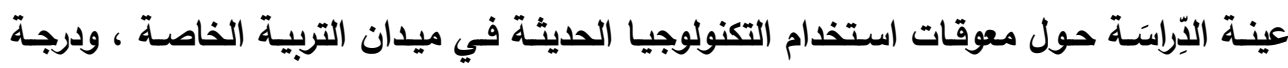

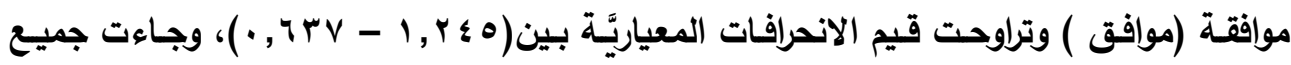

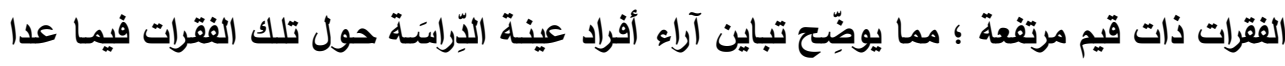

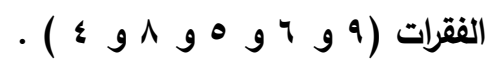

وجاءت في الترتيب الأول الفقرة رقم (^): (عدم توافر أجهزة وأدوات و وسـائل تعليمية

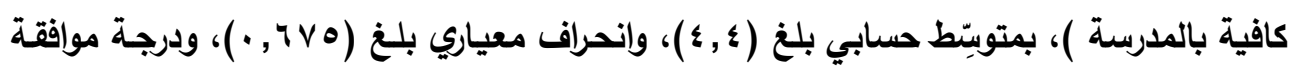

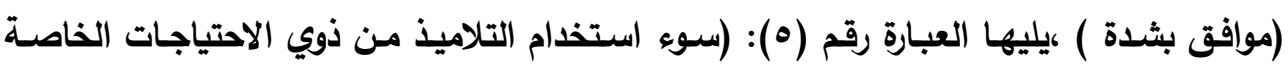

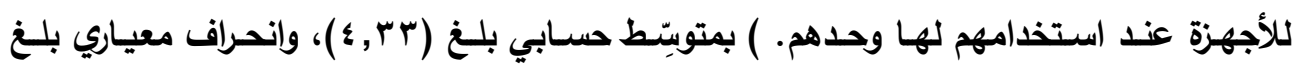
( V^^, • )، ودرجة موافقة (موافق بثدة ) ،بينما جاءت في الترتيب الأخير العبارة رقم ( • ():

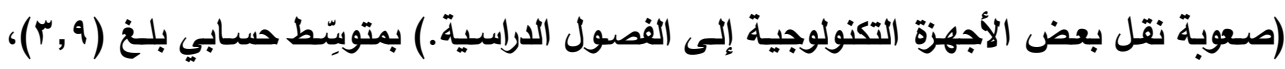

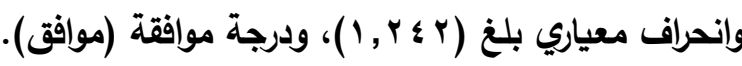

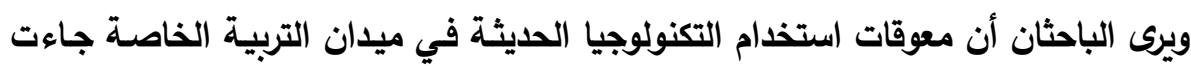
بلرجة كبيرة من وجهة نظر أفراد عينة الآِراسَسة وذلك بسبب عدم توافر أجهزة وأدوات و وسـائل 


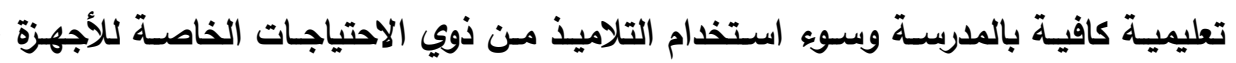

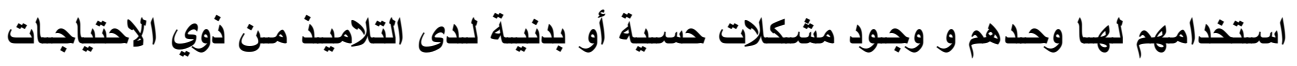
الخاصة والتي تحد من قدرتهم على استخدام الوسيلة التعليمية .

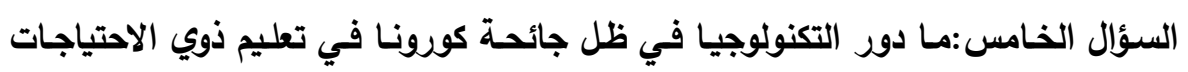
الخاصة ؟

للتعرف على دور التكنولوجيا في ظل جائحة كورونا في تعليم ذوي الاحتياجات الخاصة ؛

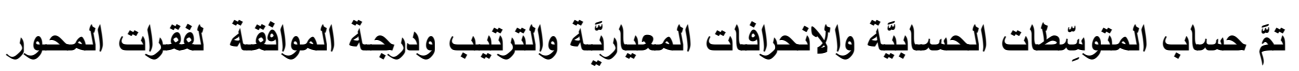

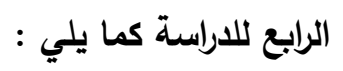

جدول) ؛ - ه (المتوبِّطات الحسابيَّة والانحرافات المعياريَّة والترتيب لعبارات البعد الخامس

\begin{tabular}{|c|c|c|c|c|}
\hline الرتبة & 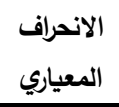 & المتوسط & 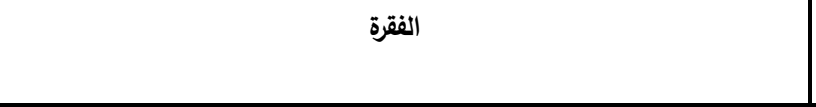 & الفقرة \\
\hline r & qur. & $\varepsilon, \varepsilon$. & |ذوي الاحتياجات الخاصنة التكولوجيا في توفير طرق وأساليب للتعليم بما يناسب كل المتعلمين من & 1 \\
\hline 7 & $\Lambda \leqslant 0$. & $\varepsilon, 1$. & المرغوب فيهاعل التكولوجيا على اكساب ذوى الاحتياجات الخاصة الأنماط السلوكية & r \\
\hline$\checkmark$ & 99. & $r, q$. & للمعاقين وذلك بتوفير خبرات حسية مناسبة التكولوجيا في التظلب على الانخاض في القدرة على التفكير المجرد & $r$ \\
\hline 1 & $\leqslant 9 \wedge$. & $\varepsilon, 7$ & الانتباه الداخلية عنده التكنولوجيا في توفر مثيرات خارجية تعوض المعوق الضعف في مثيرات & $\varepsilon$ \\
\hline$\varepsilon$ & $\wedge \wedge \vee$. & $\varepsilon, r$. & ساعدت التكنولوجيا في توفير برامج التعليم والتدريب لذوى الاحتياجات الخاصة & $\bullet$ \\
\hline$\bullet$ & vir. & $\varepsilon, 1 V$ & الاحتياجات الخاصدة التكولوجيا في توفير برامج الإعداد والتأهيل المهني والتوظيف لذوى & 7 \\
\hline$r$ & ivo. & $\varepsilon, r \wedge$ & ساعدت التكنولوجيا ذوى الاحتياجات الخاصة في تحسين قدرتهم على التواصل & 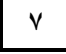 \\
\hline & $\cdot, \mathrm{v}$ & $\varepsilon, Y_{0}$ & المتوسط العام & \\
\hline
\end{tabular}

يتبين مـن الجدول السـابق أن دور التكنولوجيا في ظل جائحسة كورونـا في تعليم ذوي

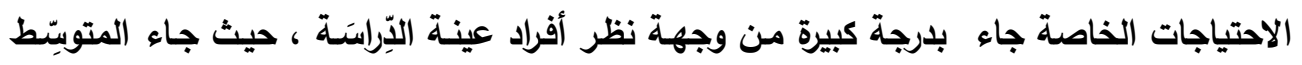

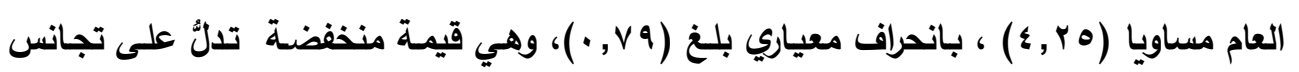


آراء أفراد عينة الدّراسَة حول دور التكنولوجيا في ظل جائحة كورونـا في تعليم ذوي الاحتياجات

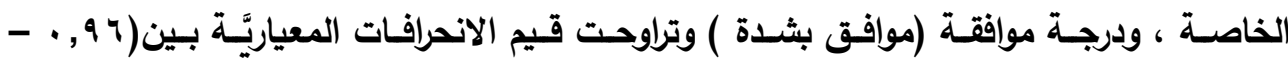

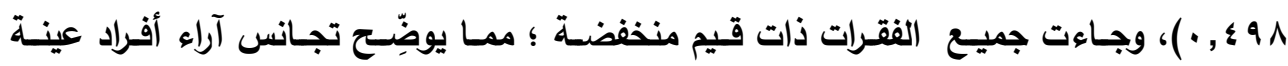

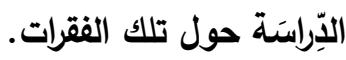
وجاءت في الترتيب الأول الفقرة رقم (؛): (ساعدت التكنولوجيا في توفر مثيرات خارجية

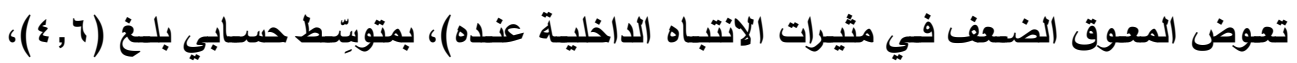

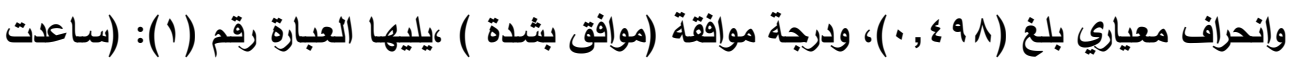

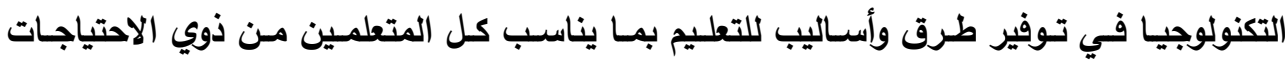

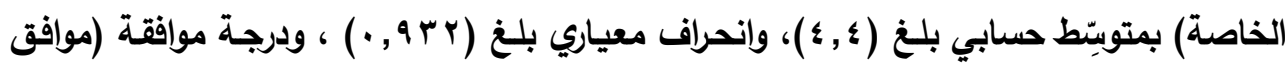

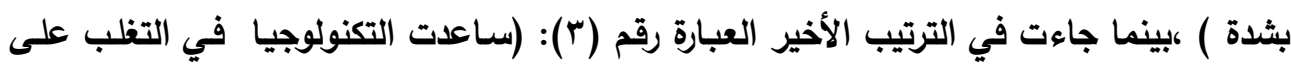

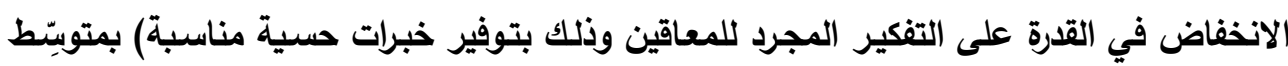

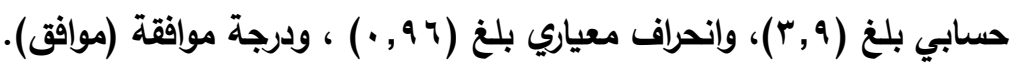

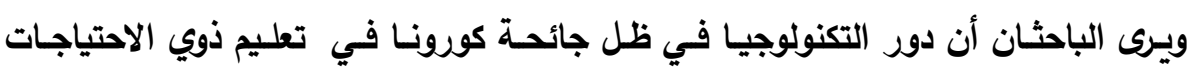

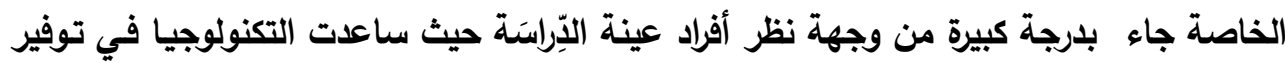

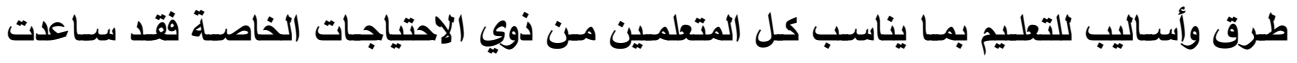
التكنولوجيا في توفر مثيرات خارجية تعوض المعوق الضعف في مثيرات الانتباه الداخلية عنده الفصل الخامس ملخص النتائج و التوصيات تمهيد: بعد أن عرض الباحثان في الفصل السابق نتائج البحث الميدانية، وذلك من خـلال عرض ألـات استجابات أفراد عينة البحث على محاور الدراسة ومعالجتها إحصائياً باستخدام مفاهيم الإحصاء الوصفي وأساليبه الإحصائية، وصولاً إلى النتائج وتحليلها وتفسيرها.

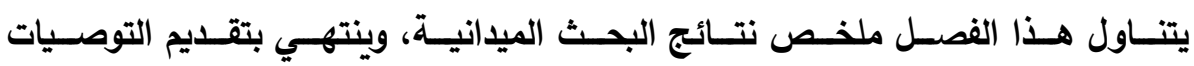
أولاً: ملخص النتائج: ويتمثل ذلك في عرض أبرز النتائج التي توصل إليها البحث فيما يتعلق بالإجابة على تساؤلاته وتحقيق أهدافه، حيث جاءت كما يلي: 
واقع استخدام التكنولوجيا الحديثة في ميدان التربية الخاصة بالمملكة العربية السعودية

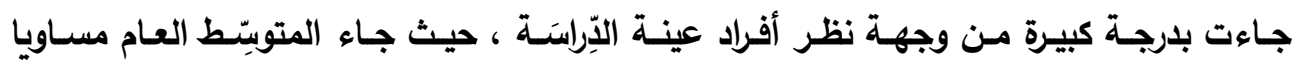

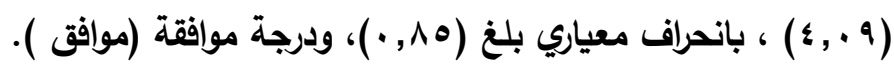

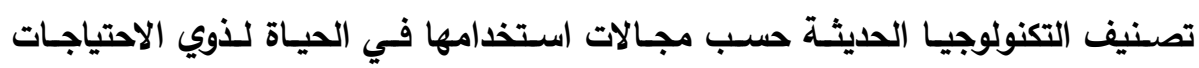

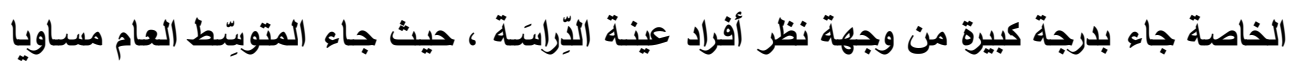

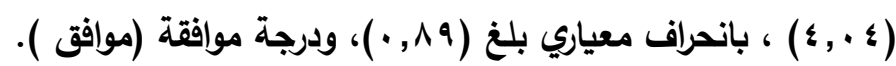

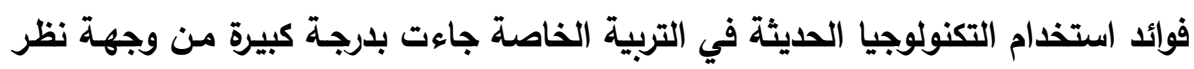

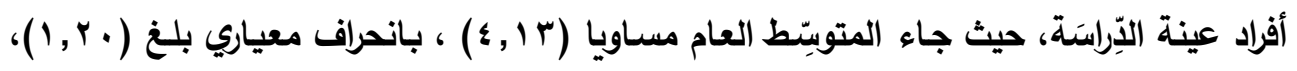
ودرجة موافقة (موافق ).

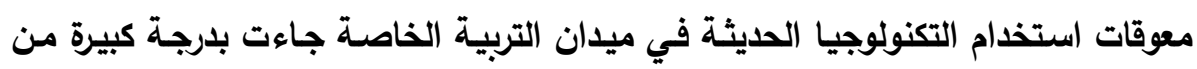

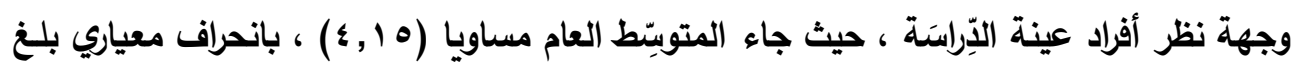
(9 9 , · ) )، ودرجة موافقة (موافق ) ).

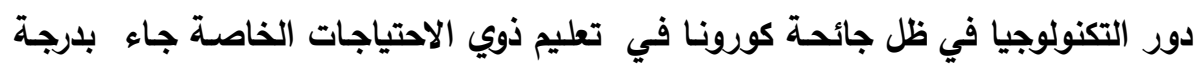

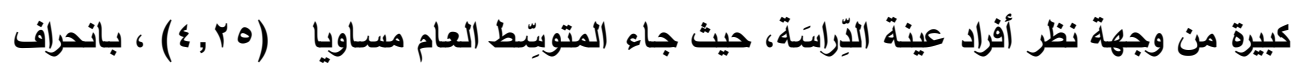

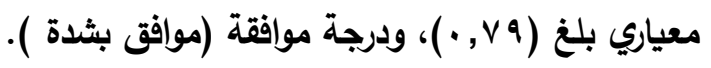

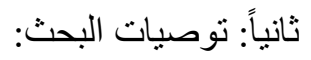
توصل الباحثان إلى عدة توصيات منها : •ضرورة توافر أجهزة وأدوات ووسائل تعليمية كافية بالمدرسة.

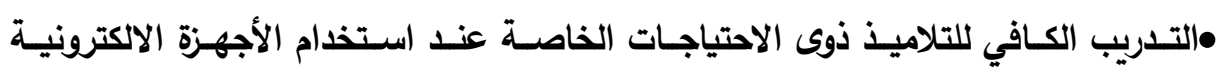
بمفردهم.

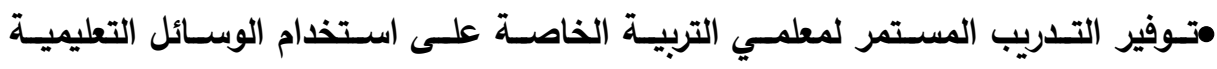
التكنولوجية. •تعريف معلمي التربية الخاصة بالدور الذى تقوم بـه الوسـائل التعليمية التكنولوجية ودورها في تحسين مستوي الشرح. مضرورة توفير فني لتثغيل وصيانة الأجهزة التعليمية بالمدرسة. •يجب ان يحتوى الكتاب المدرسي على التوجيهات التي تؤكد ضرورة استخدام الوسـائل التعليمية. 
• العمل على تخصيص ميزانية كافية لتوفير هذه الأجهزة والتقنيات التكنلوجية الحديثة في المدارس التي يوجد بها برامج صعوبات تعلم في جميع المراحل وخاصة الابتدائية.

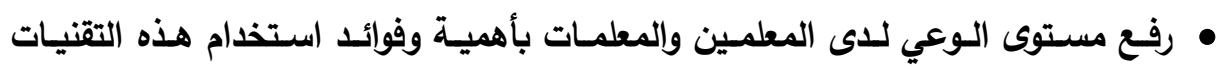

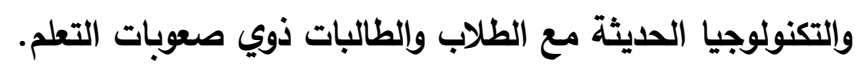

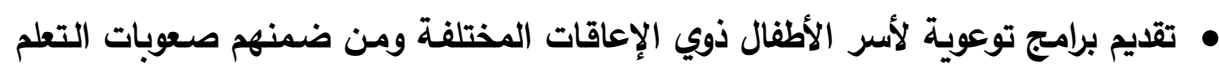

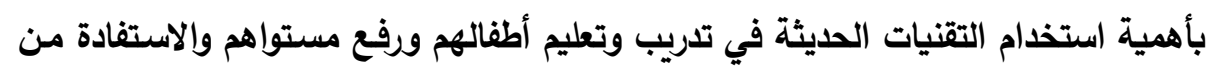
قدراتهم إلى أقصى حد ممكن. • تشـجيع القطاع الخـاص على المشـاركة في تـوفير ودعم هذه التقنيـات للأطفـال ذوي الإعاقات المختلفة ولأسرهم.

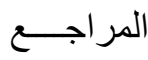

•آل حاوي، محمد (د.ت): واقع استخدام أعضـاء هيئة التدريس والههيئة المسـاندة لتقنيـة

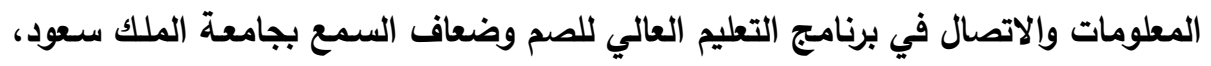

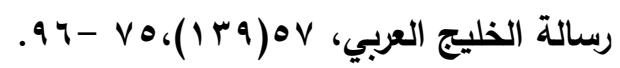

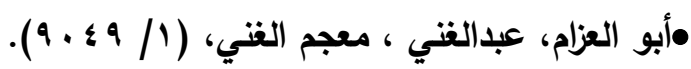

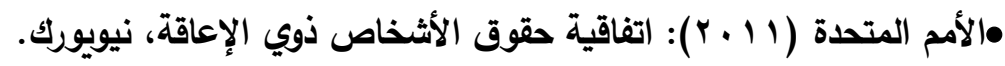

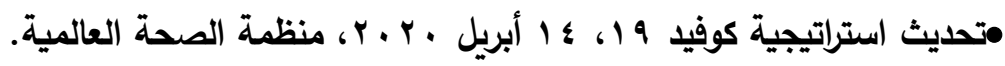

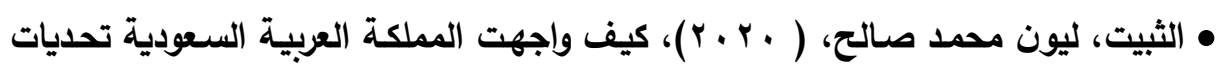

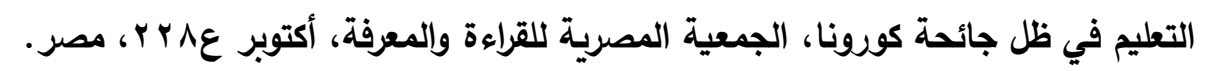

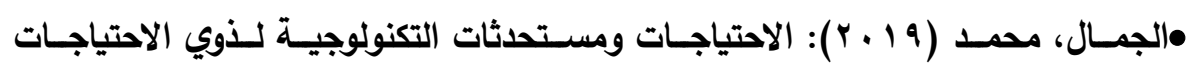

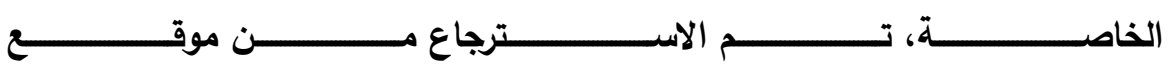
http://askzad.com/Bibliographic?service $=4$ \&imageName=y3gize Xa6Wh9mDZVill68Q..\&imageCount140\&key=Books_Bibliogra ئic

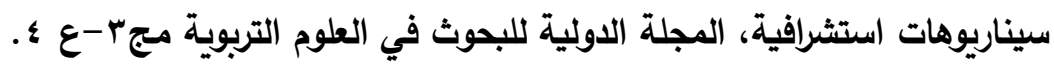

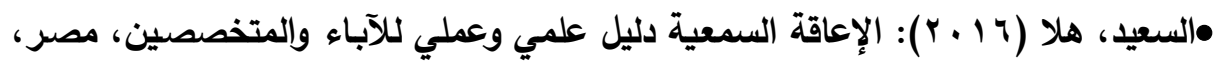

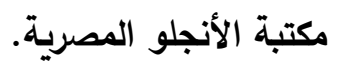


•الثراري، عبد العزيز(د.ت): تقييم فاعلية التكنولوجيا المساعدة من وجهة نظر المعوقين

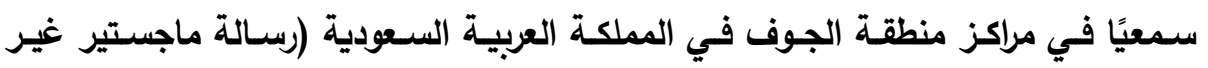
منشورة)، الجامعة الأردنية، الأردن.

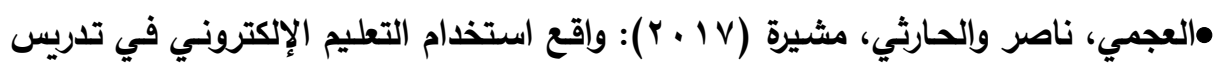
ذوات الإعاقة الفكرية البسيطة في مدارس مدينة الرياض من وجهة نظر المعلمات، مجلة

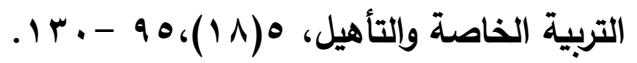

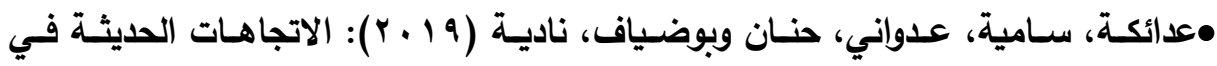

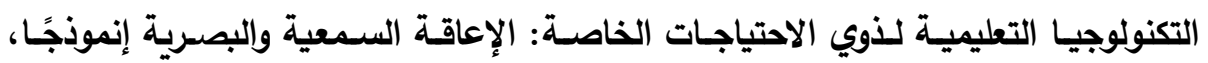

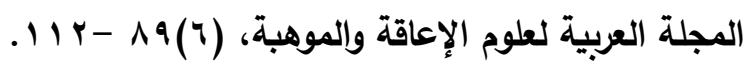

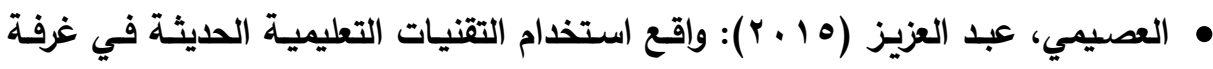
المصادر والصعوبات التي يواجها معلمي ذوي صعوبات التعلم في منطقة القصيم (رسالة ماجستير غير منشورة)، جامعة أم القرى، مكة المكرمة.

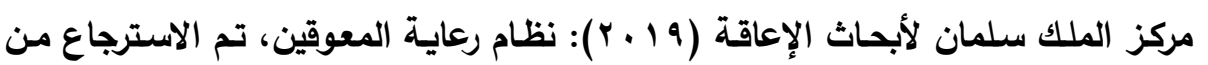

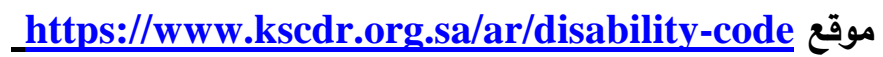
المـلاح، تامر :(2016) تكنولوجيا التعليم وذوي الاحتياجات الخاصـة الأجهزة التعليمية

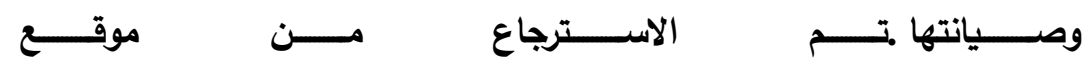
https://www.alukah.net/Books/Files/Book 7125/BookFile/technolo gy.pdf 